\title{
Photoredox-Enabled Synthesis of $\beta$-Substituted Pyrroles from Pyrrolidines
}

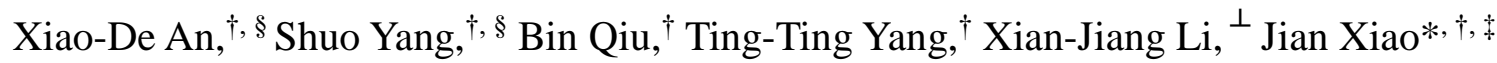
$\dagger$ College of Chemistry and Pharmaceutical Sciences, Qingdao Agricultural University, Qingdao 266109, China $\$$ School of Marine Science and Engineering, Qingdao Agricultural University, Qingdao, 266109, China

${ }^{\perp}$ Shandong Kangqiao Biotechnology Co. Ltd., Binzhou, 256500, China

E-mail: chemjianxiao@163.com.

\section{Supporting Information}

\section{Table of Contents}

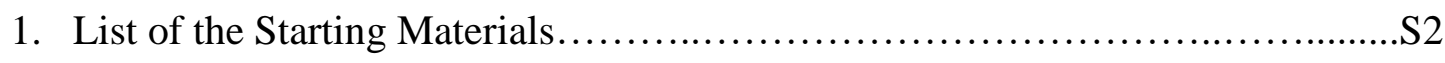

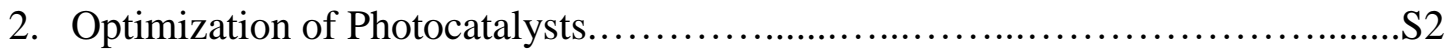

3. Reaction Set-up for Synthesis of $\beta$-Substituted Pyrroles..........................S3

4. Mechanistic Study of Aromatization.......................................... 3

5. NMR Spectra for All Compounds........................................ 5 


\section{Scheme S1. List of the Starting Materials}

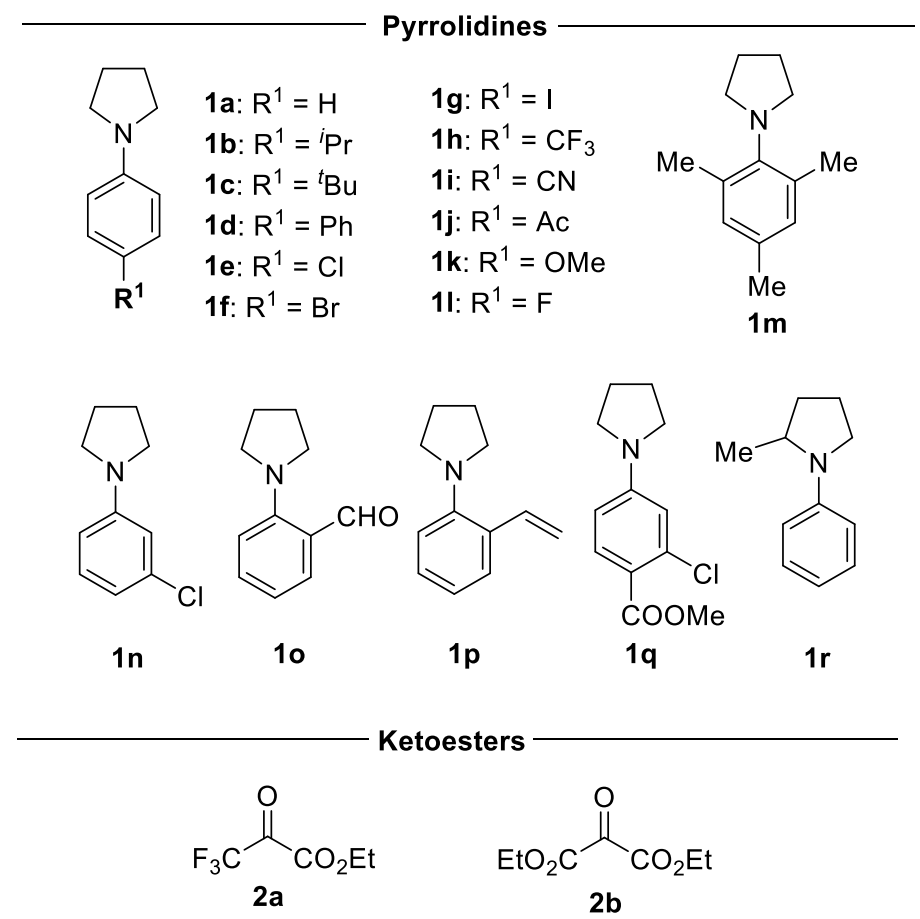

\section{Table S1. Optimization of Photocatalysts. ${ }^{a}$}<smiles>c1ccc(N2CCCC2)cc1</smiles>

$1 a$

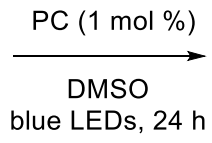

blue LEDs, $24 \mathrm{~h}$

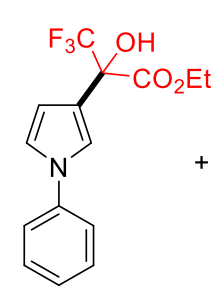

$3 \mathbf{a}$

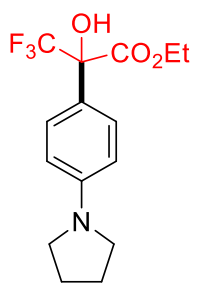

$3 a^{\prime}$

$\begin{array}{cccc}\text { entry } & \text { photocatalysts } & \text { yield of } \mathbf{3 a}(\%)^{b} & \text { yield of } \mathbf{3} \mathbf{a}^{\prime}(\%)^{b} \\ 1 & \text { Eosin } \mathrm{Y} & 29 & \text { trace } \\ 2 & \text { Rhodamine B } & 19 & \text { trace } \\ 3 & \mathrm{Ru}(\mathrm{bpy})_{3}\left(\mathrm{PF}_{6}\right)_{2} & 33 & \text { trace } \\ 4 & \mathrm{Ru}(\mathrm{bpy})_{3} \mathrm{Cl}_{2} \cdot \mathrm{H}_{2} \mathrm{O} & 36 & \text { trace } \\ 5 & \mathrm{Ir}(\mathrm{ppy})_{2}(\mathrm{dtbbpy}) \mathrm{PF}_{6} & 53 & \text { trace } \\ 6 & \mathrm{Ir}\left[\mathrm{dF}\left(\mathrm{CF}_{3}\right) \mathrm{ppy}_{2}(\mathrm{dtbbpy}) \mathrm{PF}_{6}\right. & 53 & \text { trace } \\ 7 & \mathrm{Ir}(\mathrm{ppy})_{3} & 27 & \text { trace } \\ 8 & - & - & 66 \%\end{array}$

${ }^{a}$ Reaction conditions: a solution of $1 \mathrm{a}(0.1 \mathrm{mmol}), \mathbf{2 a}(0.25 \mathrm{mmol}), \mathrm{PC}(0.001 \mathrm{mmol})$ in the DMSO $(1.0 \mathrm{~mL})$ was irradiated by blue LED strips for $24 \mathrm{~h}$ under an air atmosphere. ${ }^{b 1} \mathrm{H}$ NMR yield. 


\section{Scheme S2. Reaction Set-up for Synthesis of $\beta$-Substituted Pyrroles.}

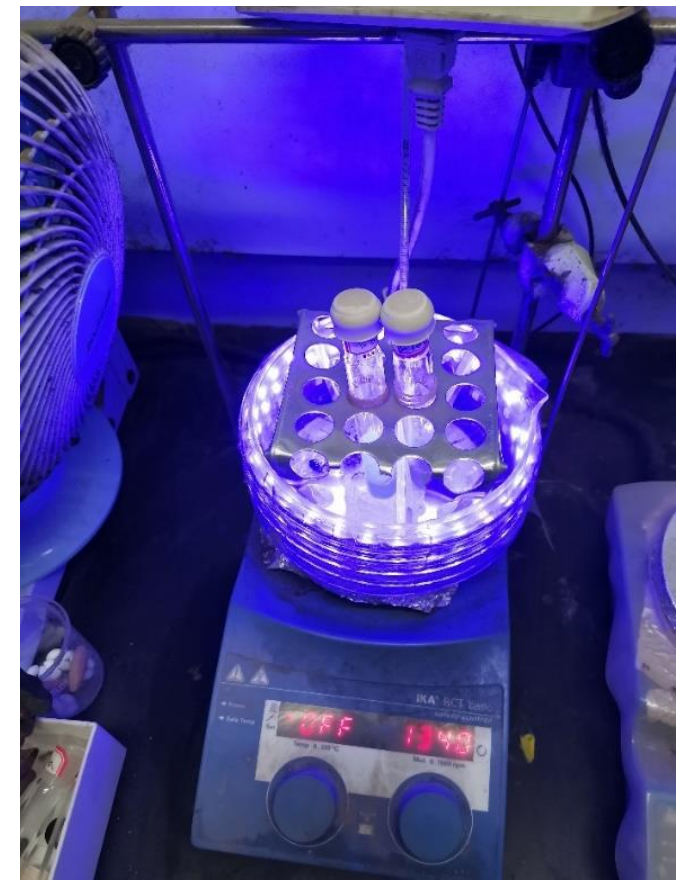

\section{Reaction set-up}

The LED light Strips (OPPLE 12-LE-38465, $4.5 \mathrm{~W}, 435 \mathrm{~nm}$ ) are used as light source. The distance between the light source and the irradiation vessel is about $7 \mathrm{~cm}$.

\section{Mechanistic Study of Aromatization}

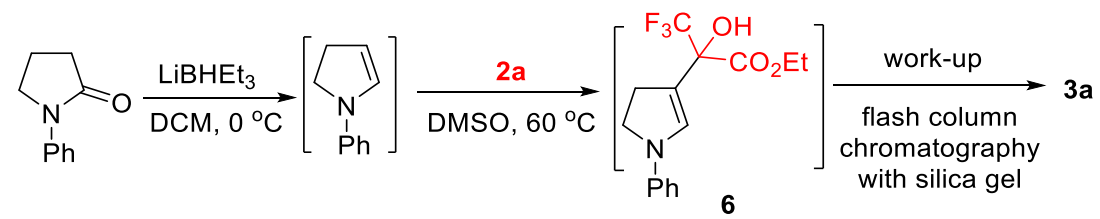

1-phenylpyrrolidin-2-one $(806.0 \mathrm{mg}, 1.0 \mathrm{mmol})$ was added into an oven-dried $100 \mathrm{~mL}$ reaction tube which was equipped with a rubber stopper and magnetic stir. The flask was evacuated and backfilled with $\mathrm{N}_{2}$ for 3 times. Then, DCM $(25 \mathrm{~mL})$ was added. The reaction mixture was stirred at $0{ }^{\circ} \mathrm{C}$ for $30 \mathrm{~min}$, and then $\mathrm{LiBHEt}_{3}(1.1 \mathrm{mmol}, 1.1$ equiv.) was added into this system via a syringe. After stirring at $0{ }^{\circ} \mathrm{C}$ for $10 \mathrm{~min}, \mathbf{2 a}(1.1 \mathrm{mmol}, 1.1$ equiv.) was then added and the reaction mixture was stirred at $60{ }^{\circ} \mathrm{C}$ for $10 \mathrm{~h}$. The progress of the reaction was monitored by TLC, and a new spot $\mathbf{A}$ appeared. After the reaction was completed, the solvent was evaporated and the residue was subjected to a flash silica gel chromatography (EtOAc : hexane $=1: 20)$. Finally, the isolated product was $\mathbf{3 a}$, which is different from the above spot $\mathbf{A}$ on 
TLC. This result suggested that the aromatization of the $\alpha, \beta$-unsaturated amine $\mathbf{6}$ could be achieved by the atmospheric oxygen involved oxidation. 


\section{NMR Spectra for All Compounds}

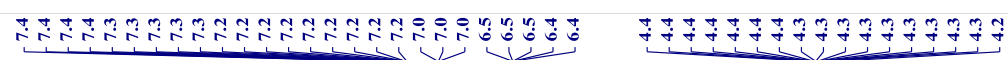

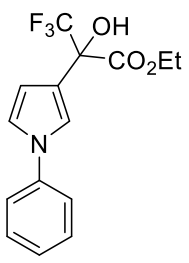

$3 a$

${ }^{1} \mathrm{H}$ NMR

$\mathrm{CDCl}_{3}, 500 \mathrm{MHz}$
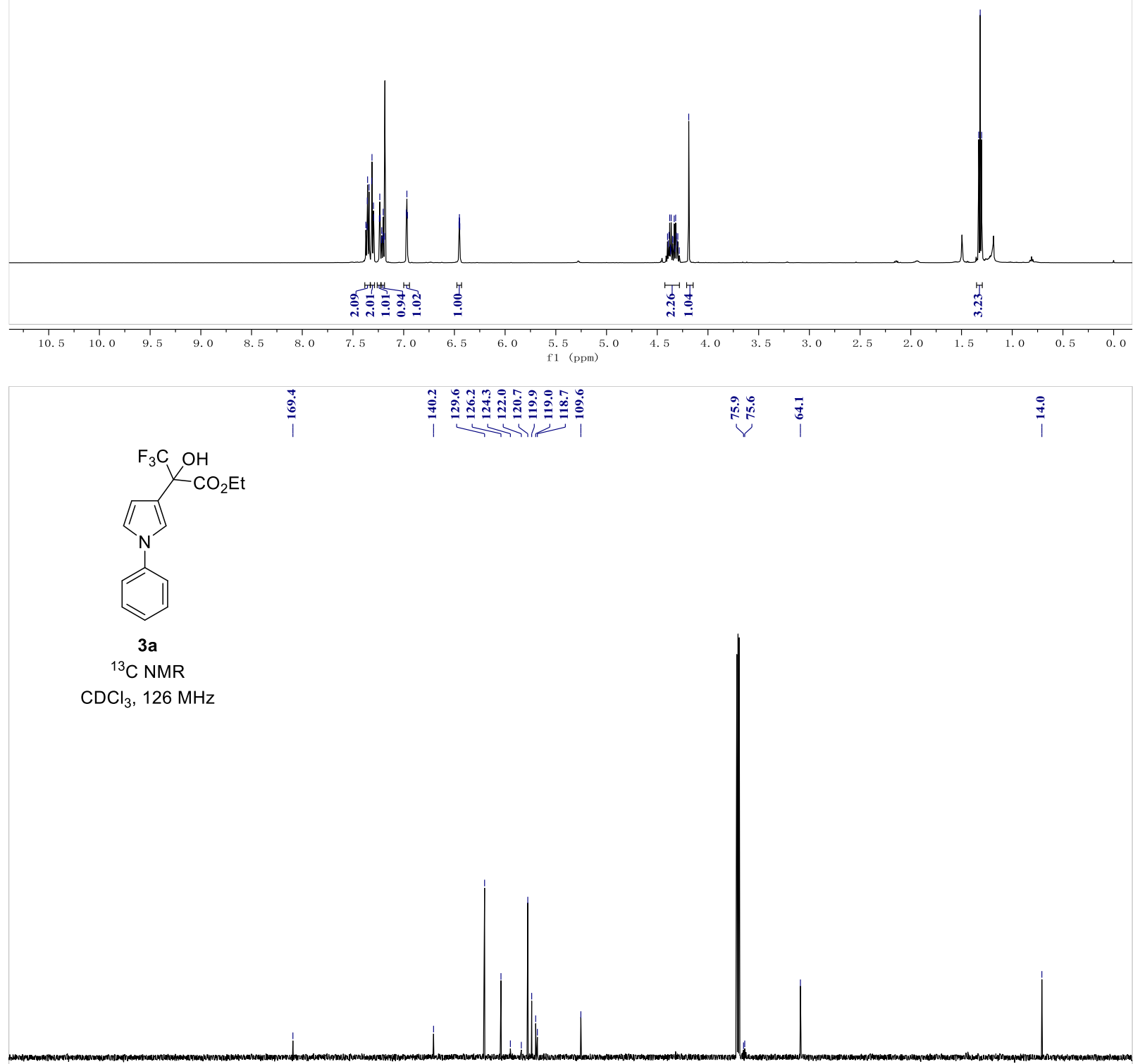

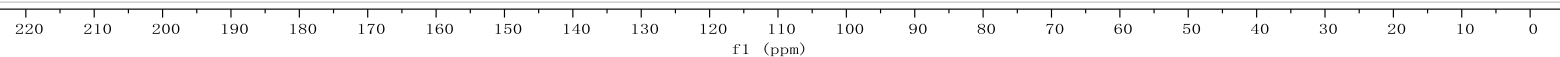




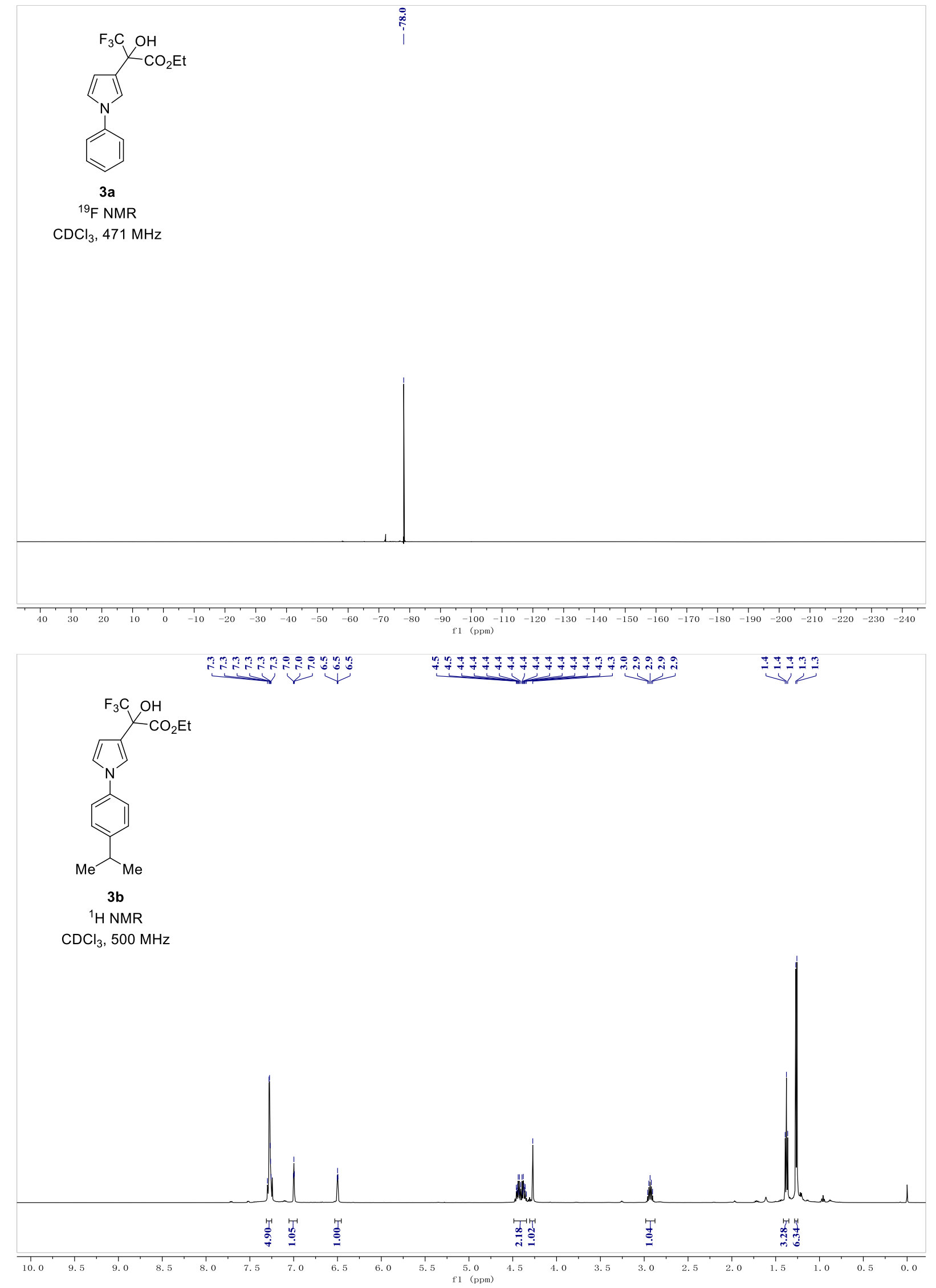



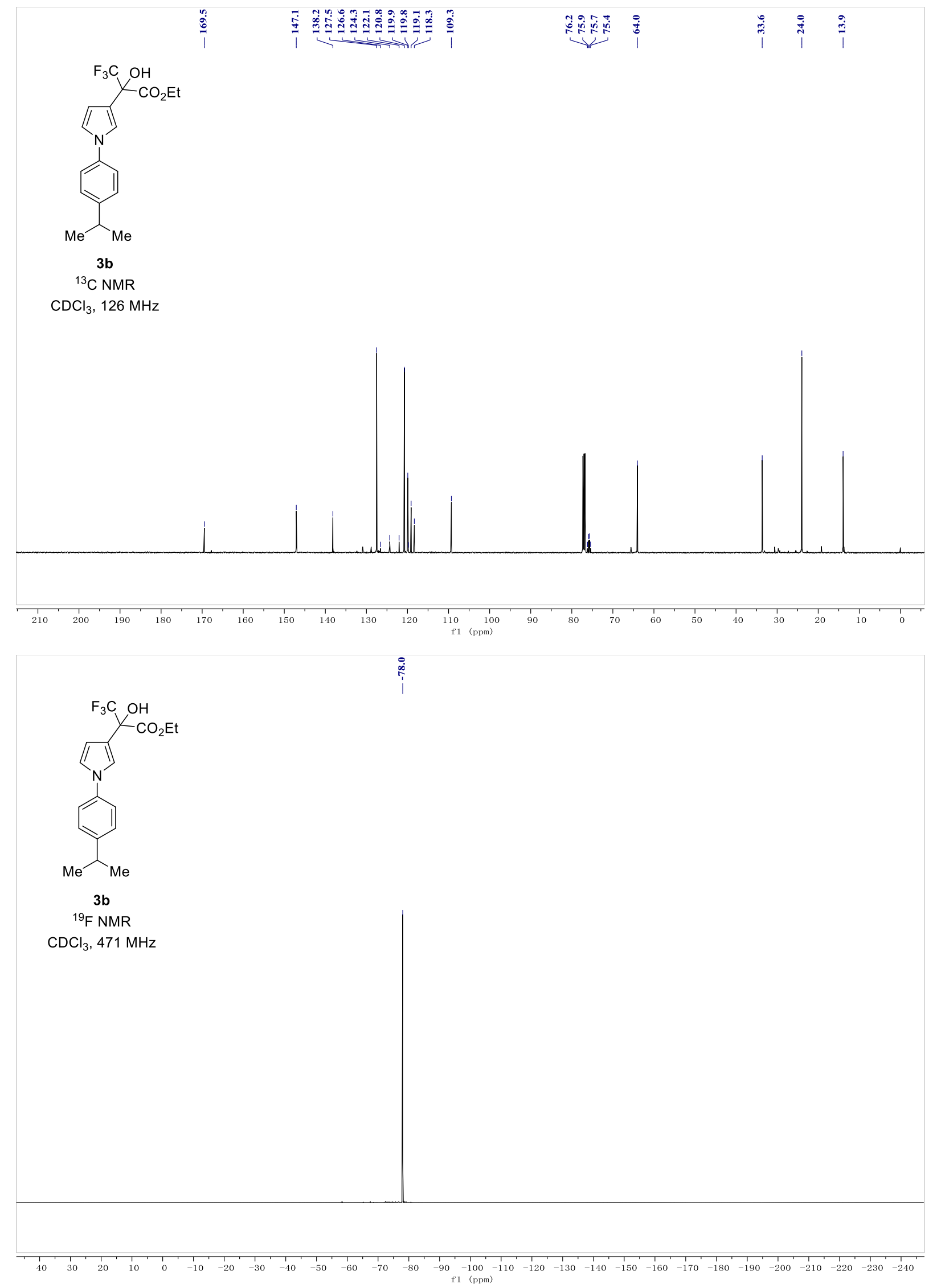

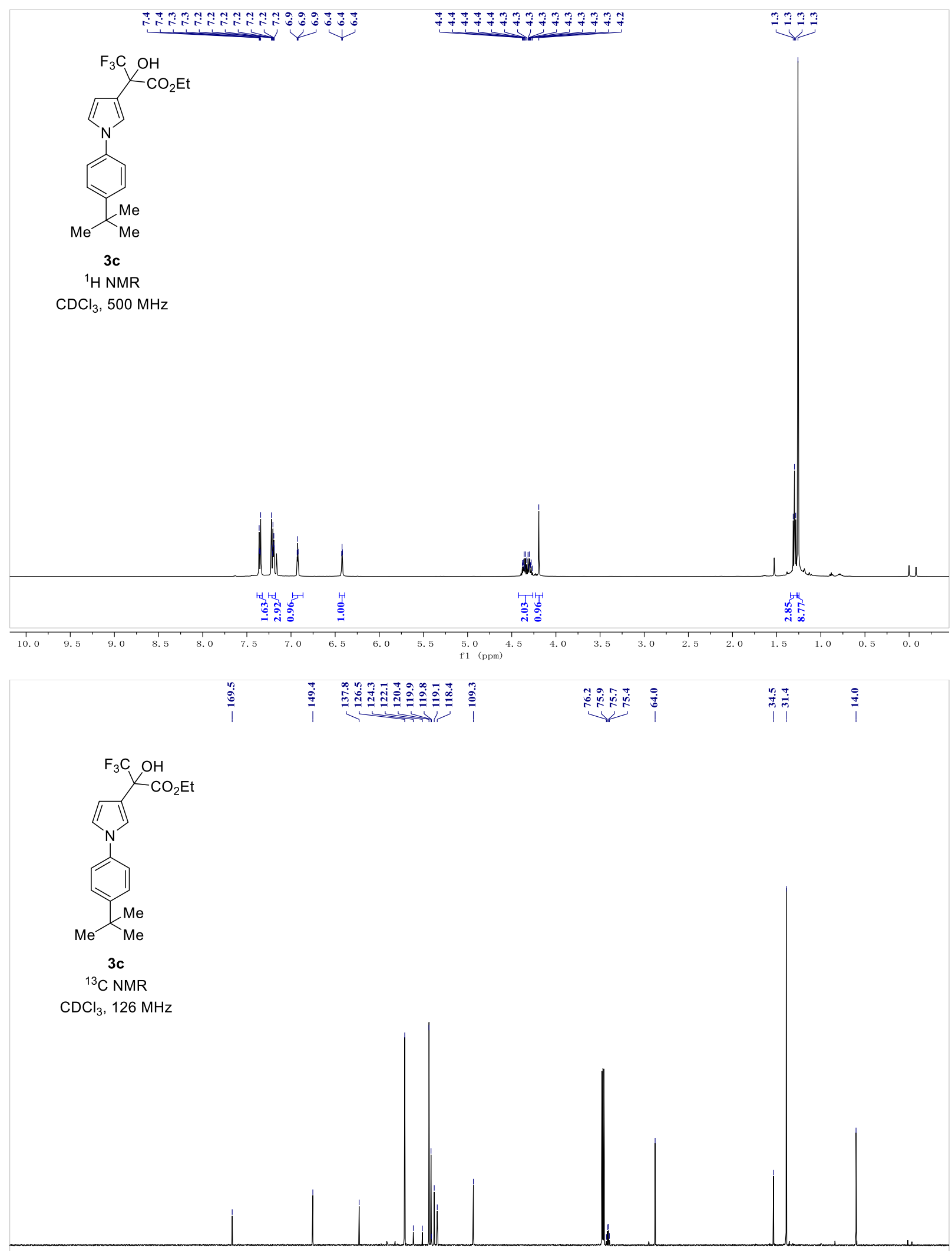

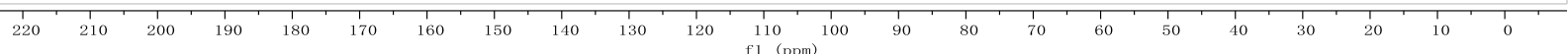




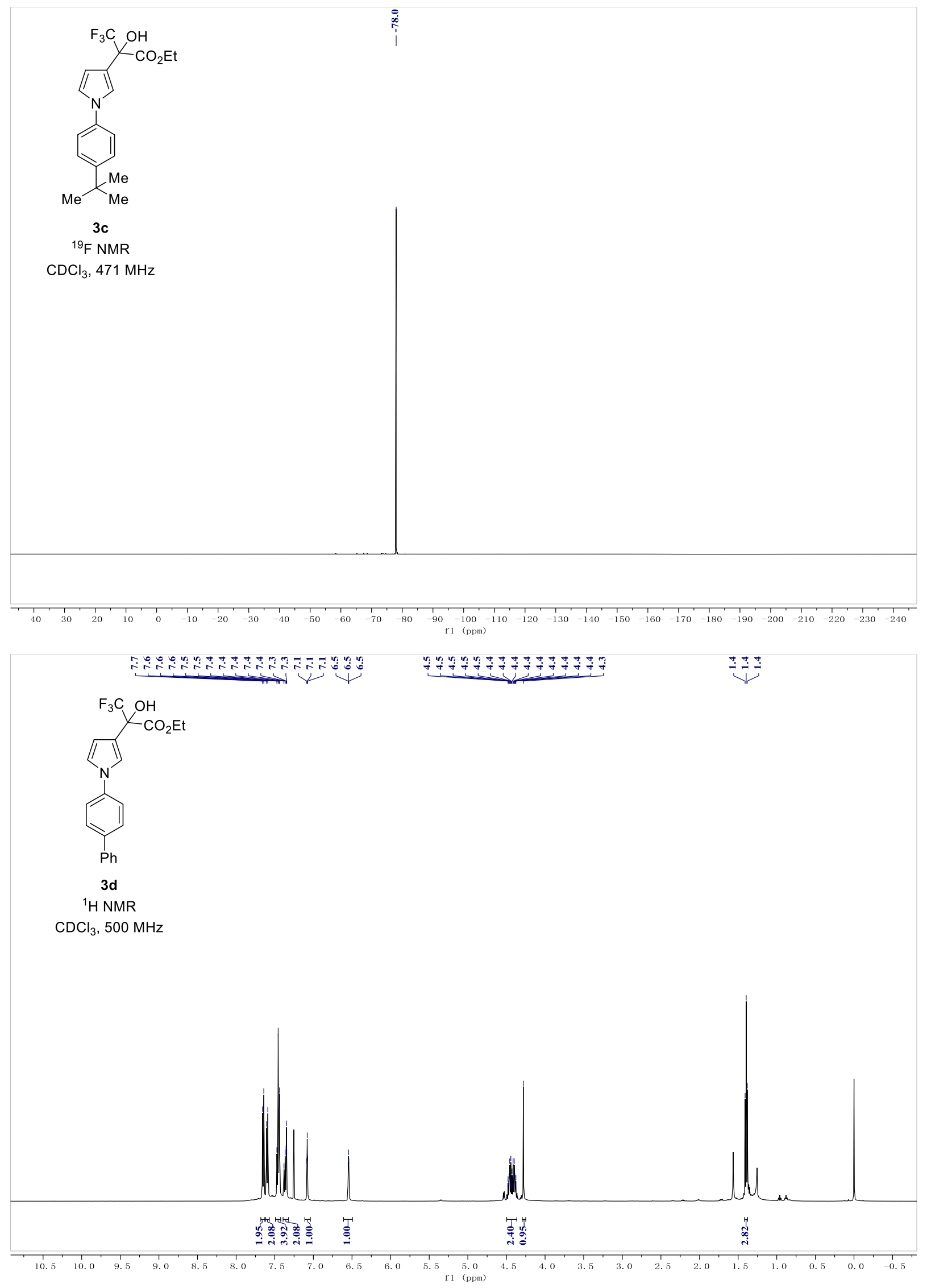



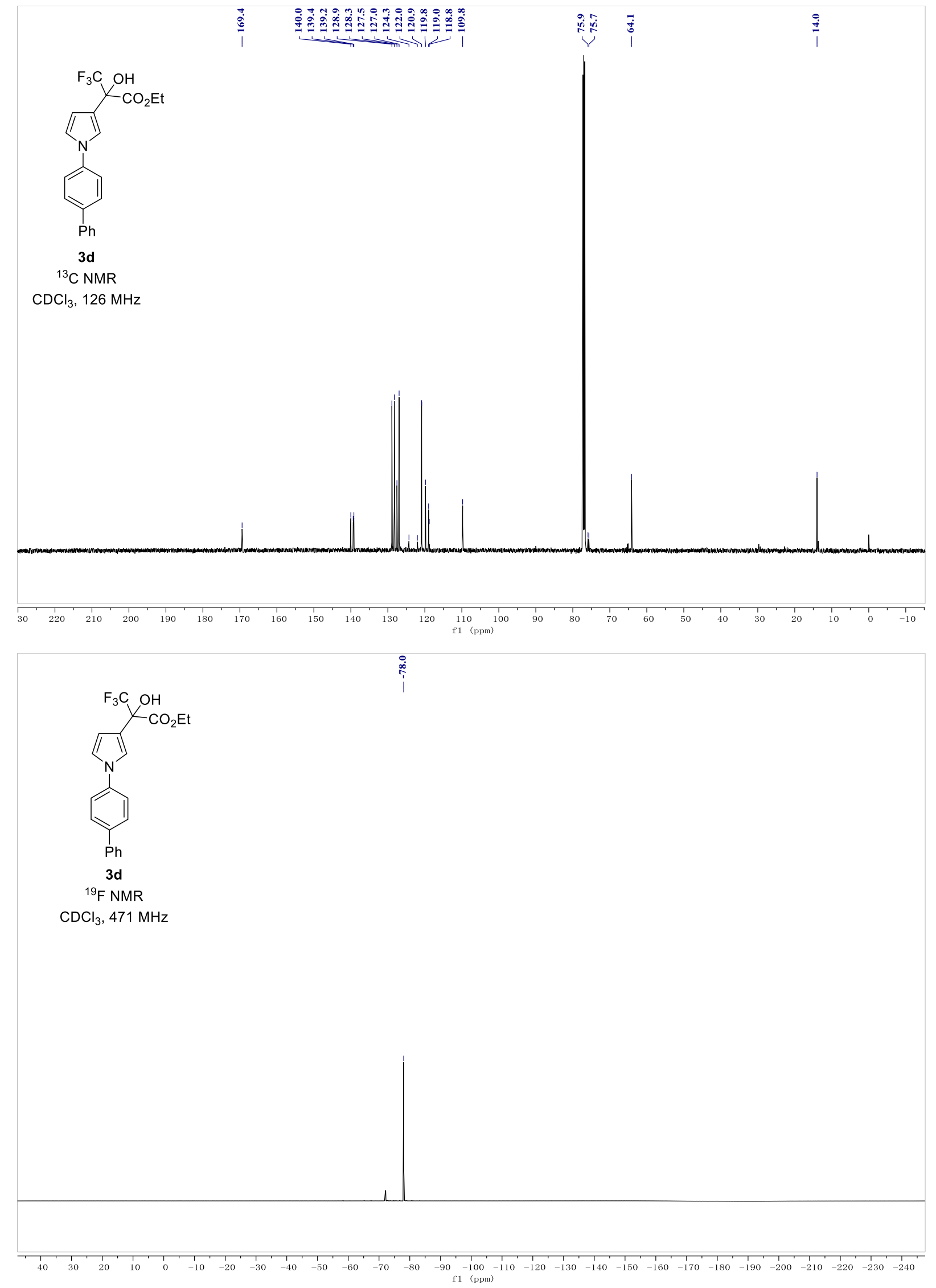


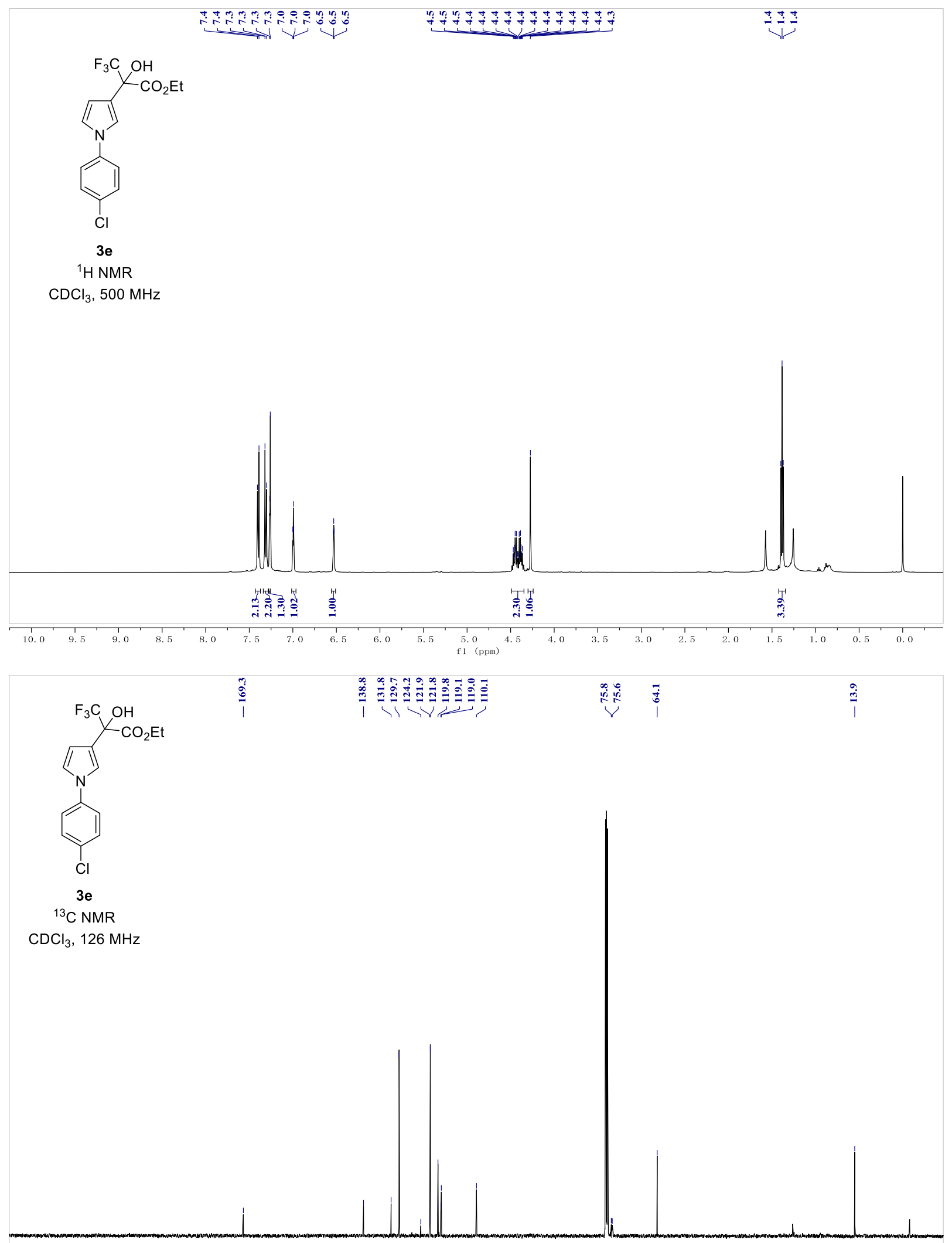

${ }_{3}$
${ }^{13} \mathrm{CNMR}$
$\mathrm{CDCl}_{3}, 126 \mathrm{MHz}$

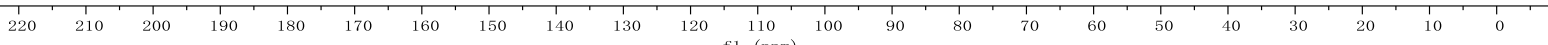




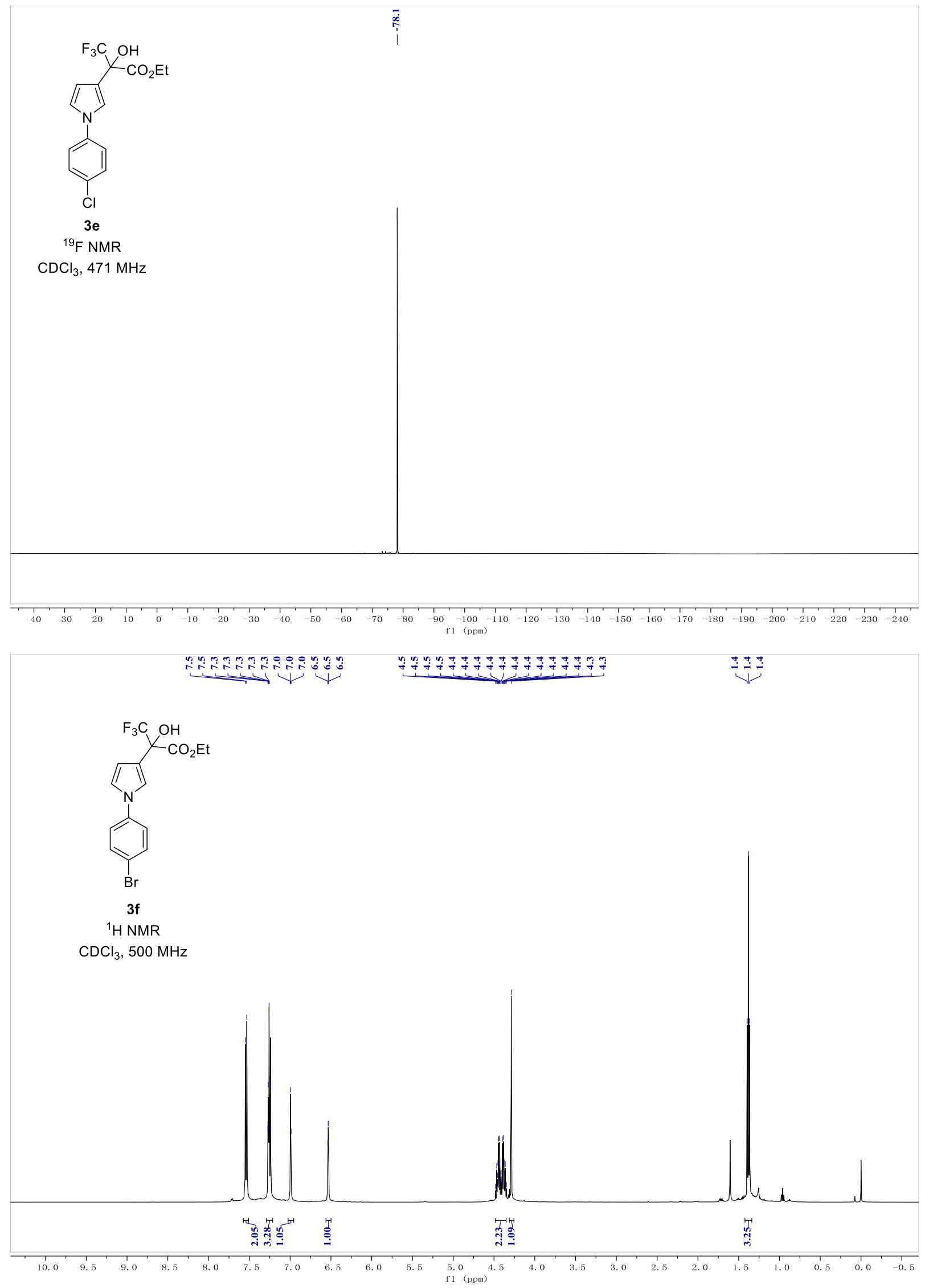



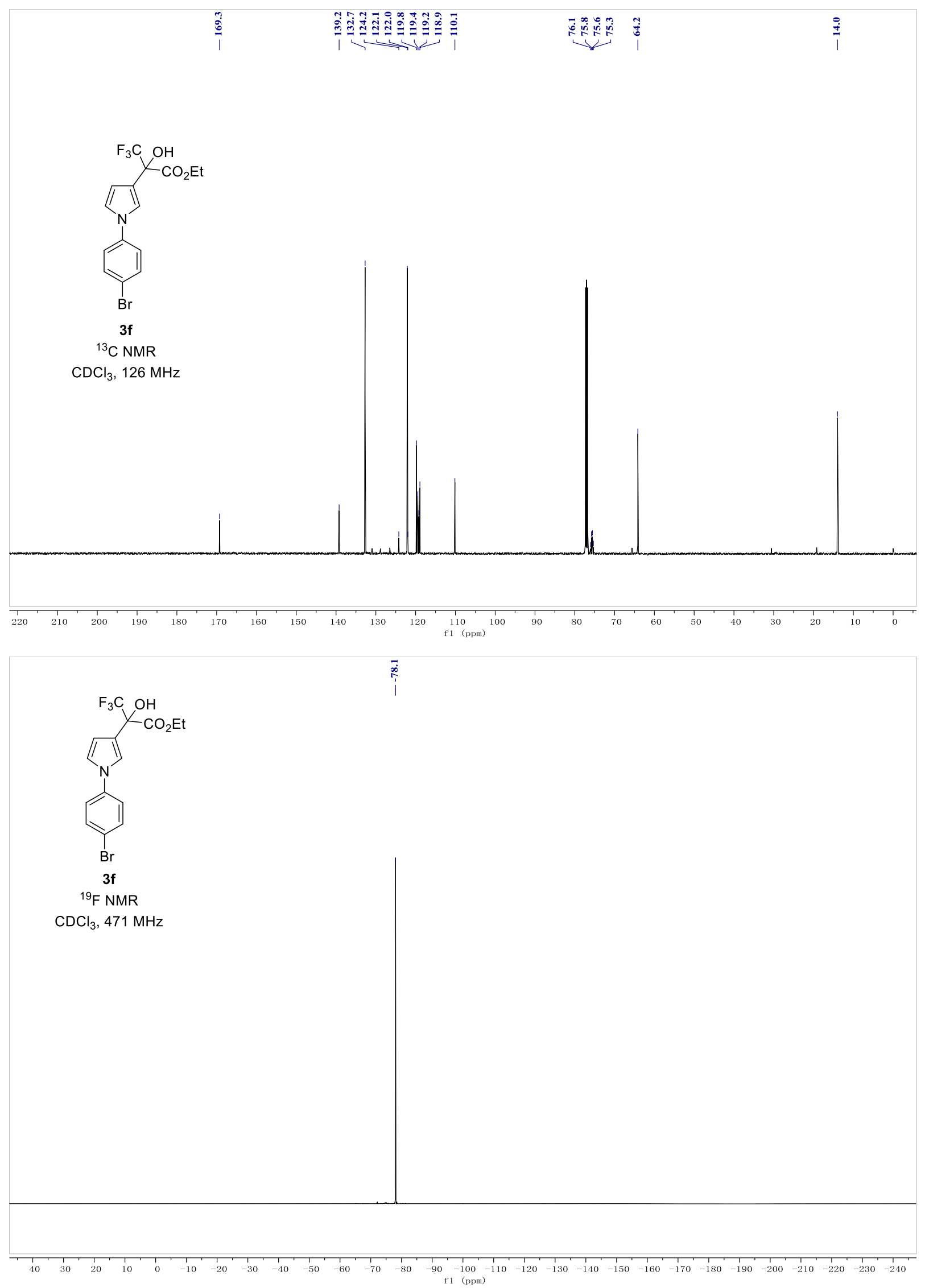


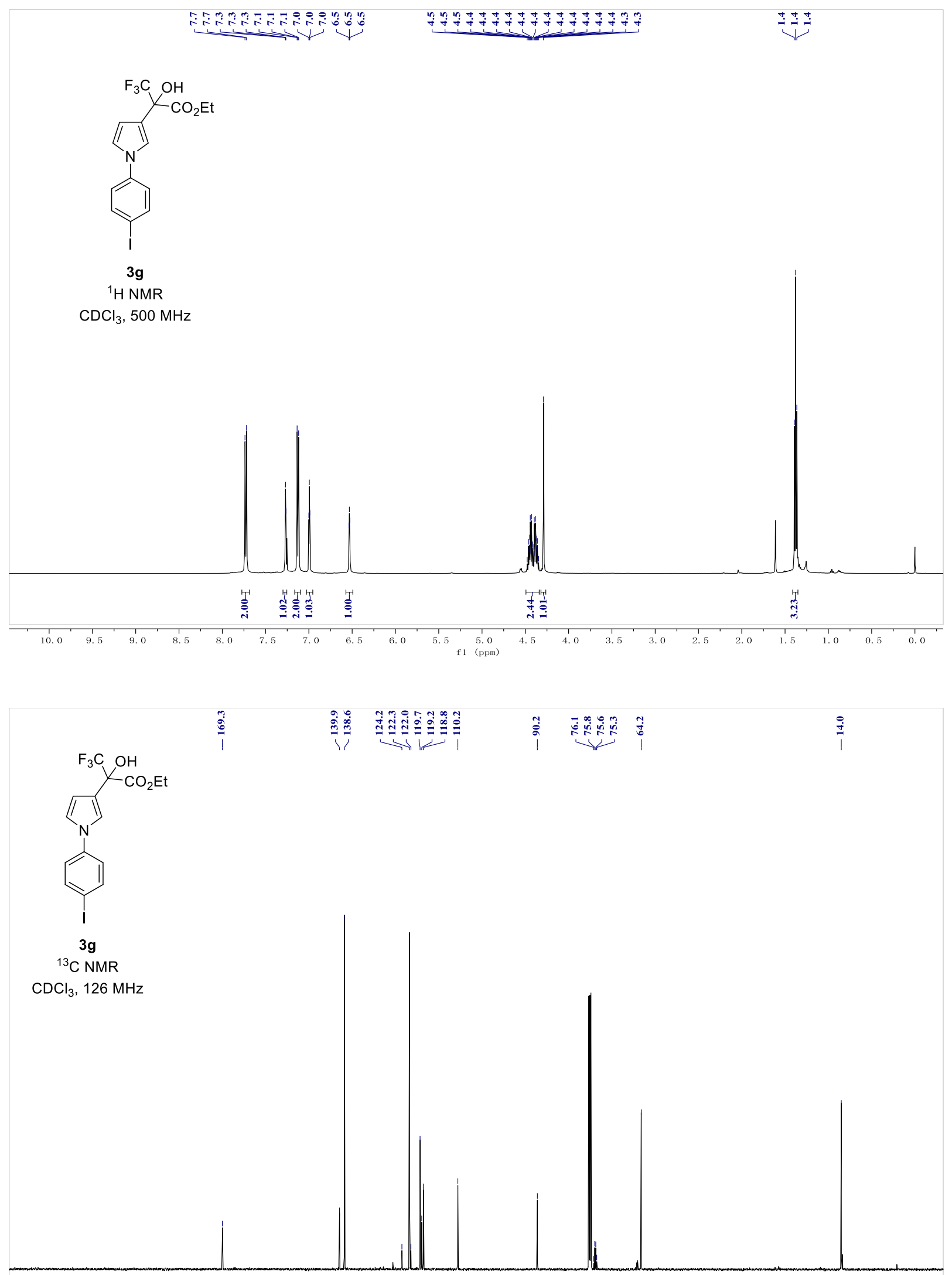

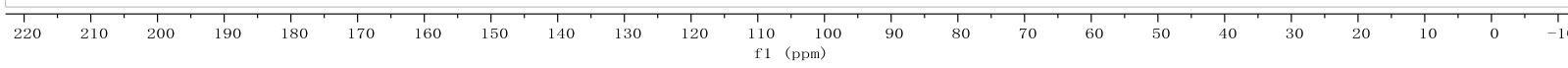




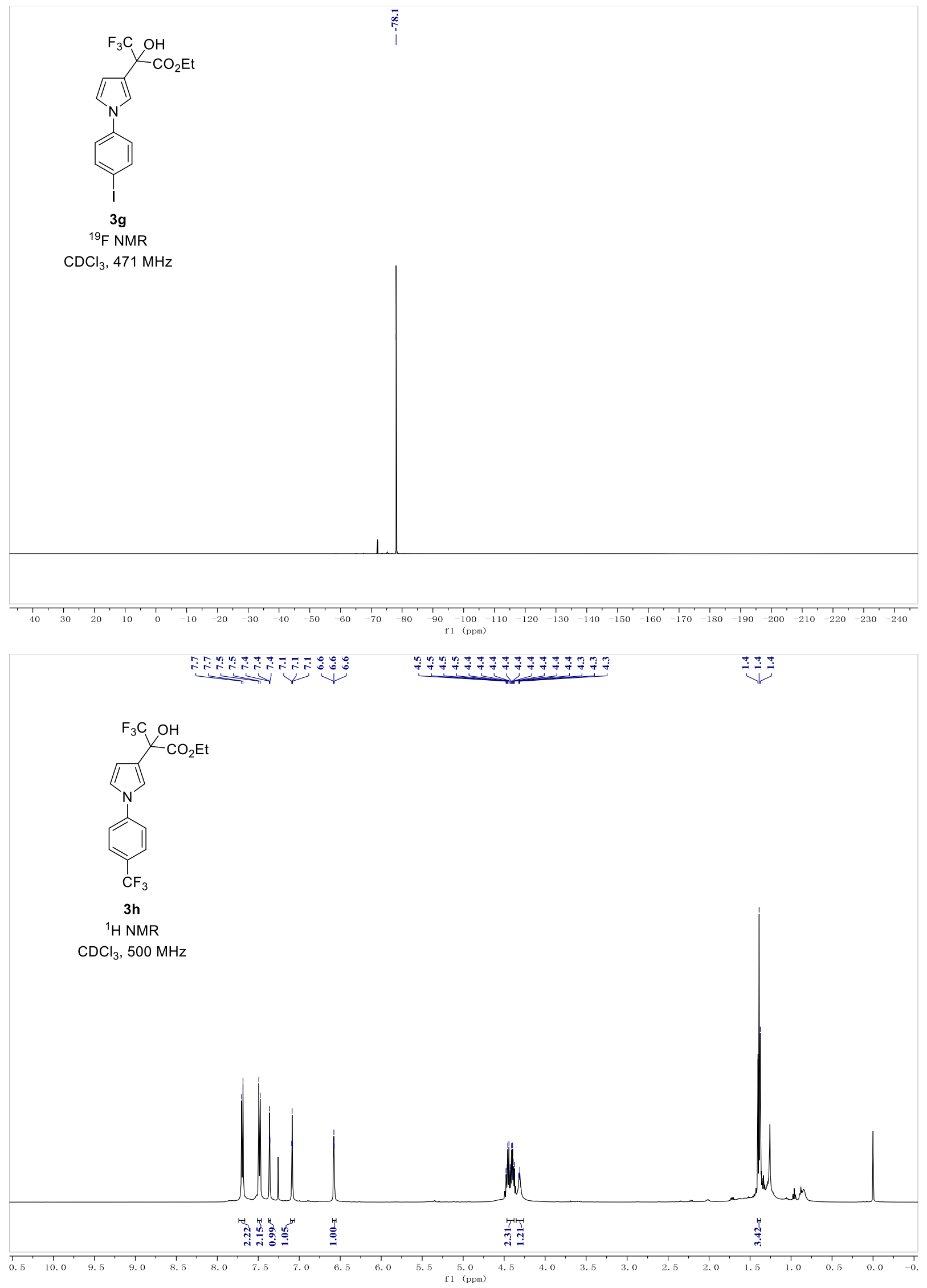



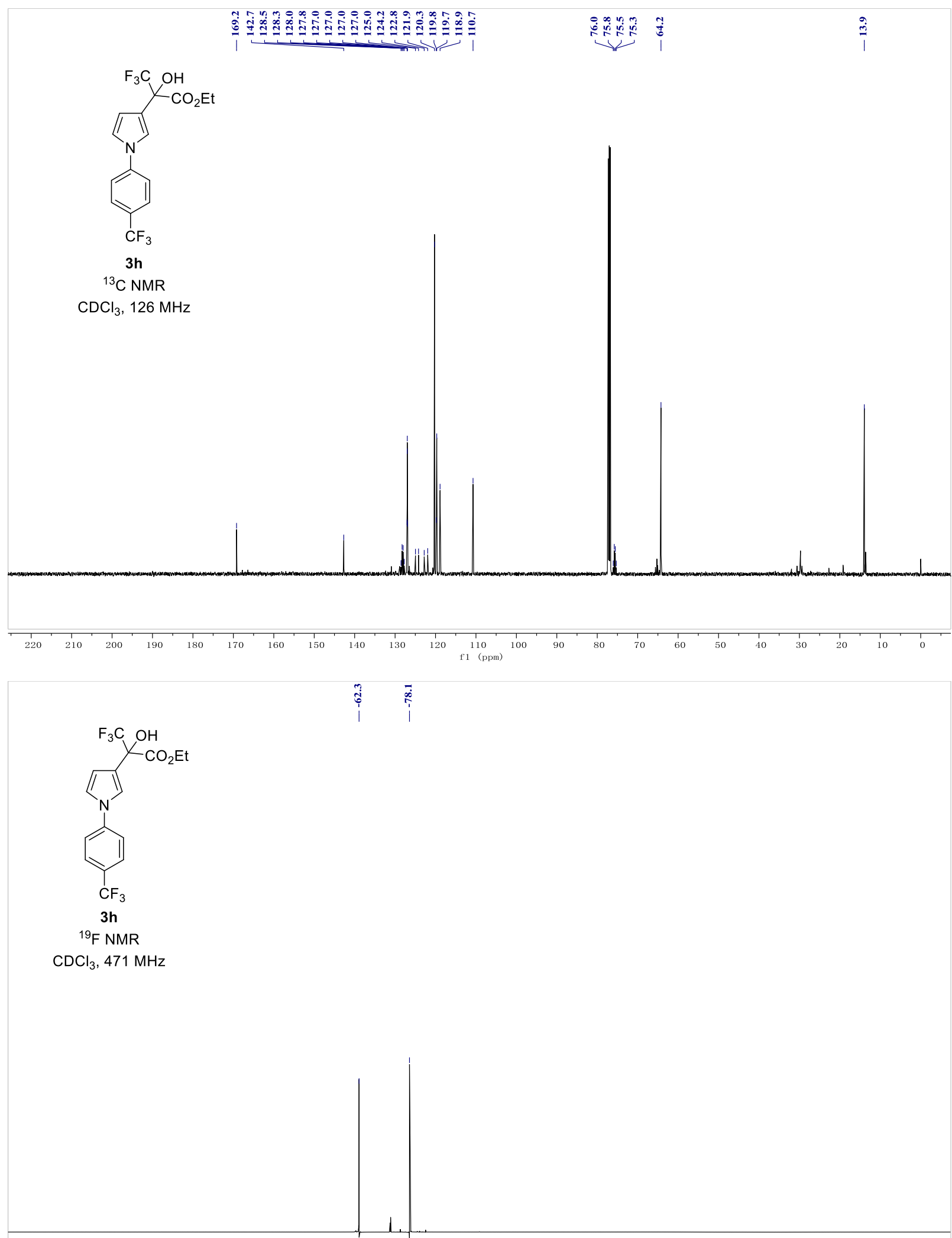

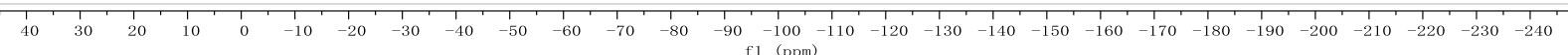




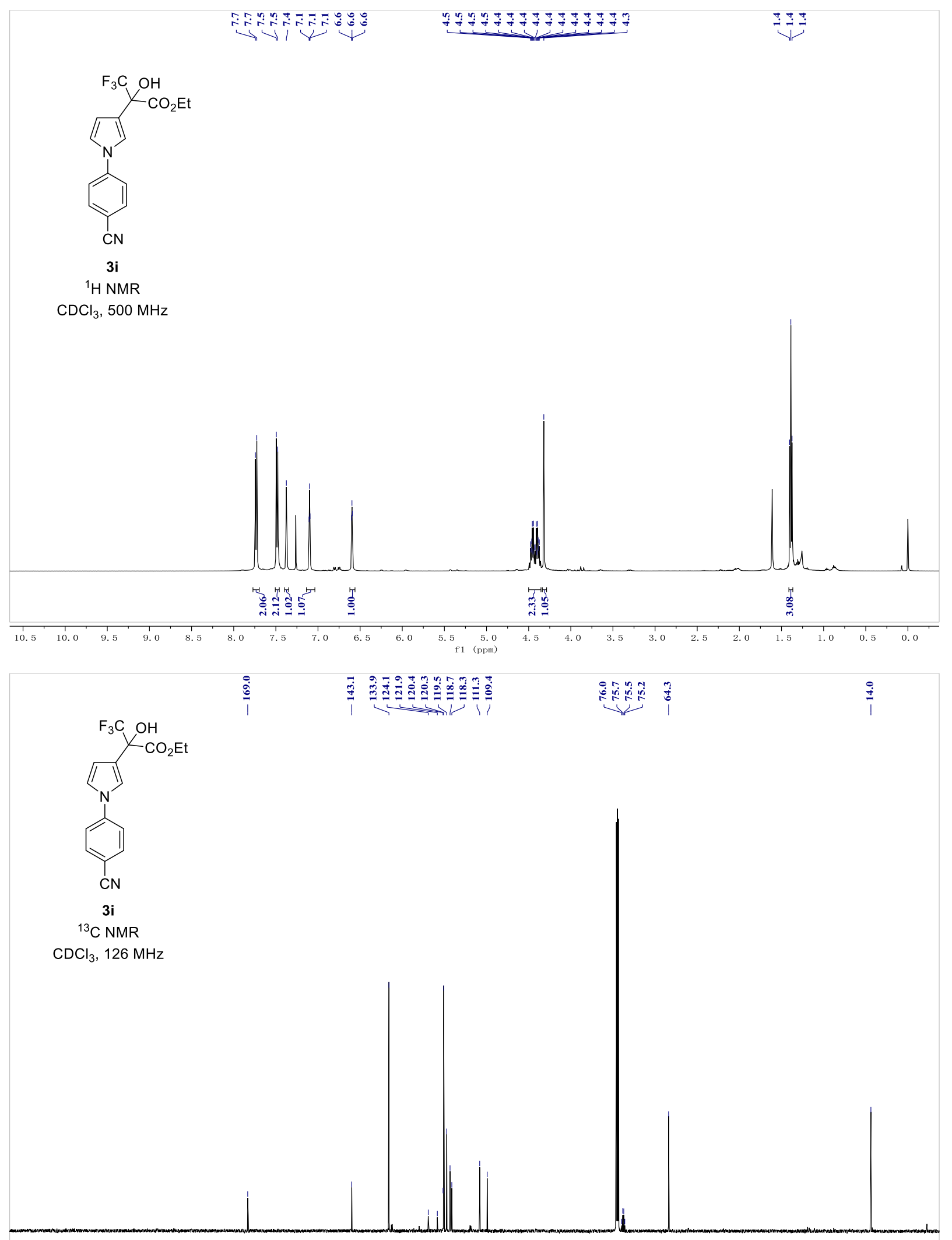

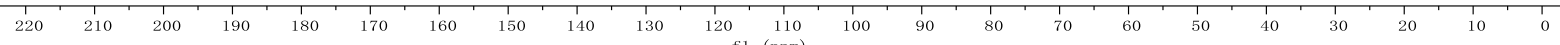




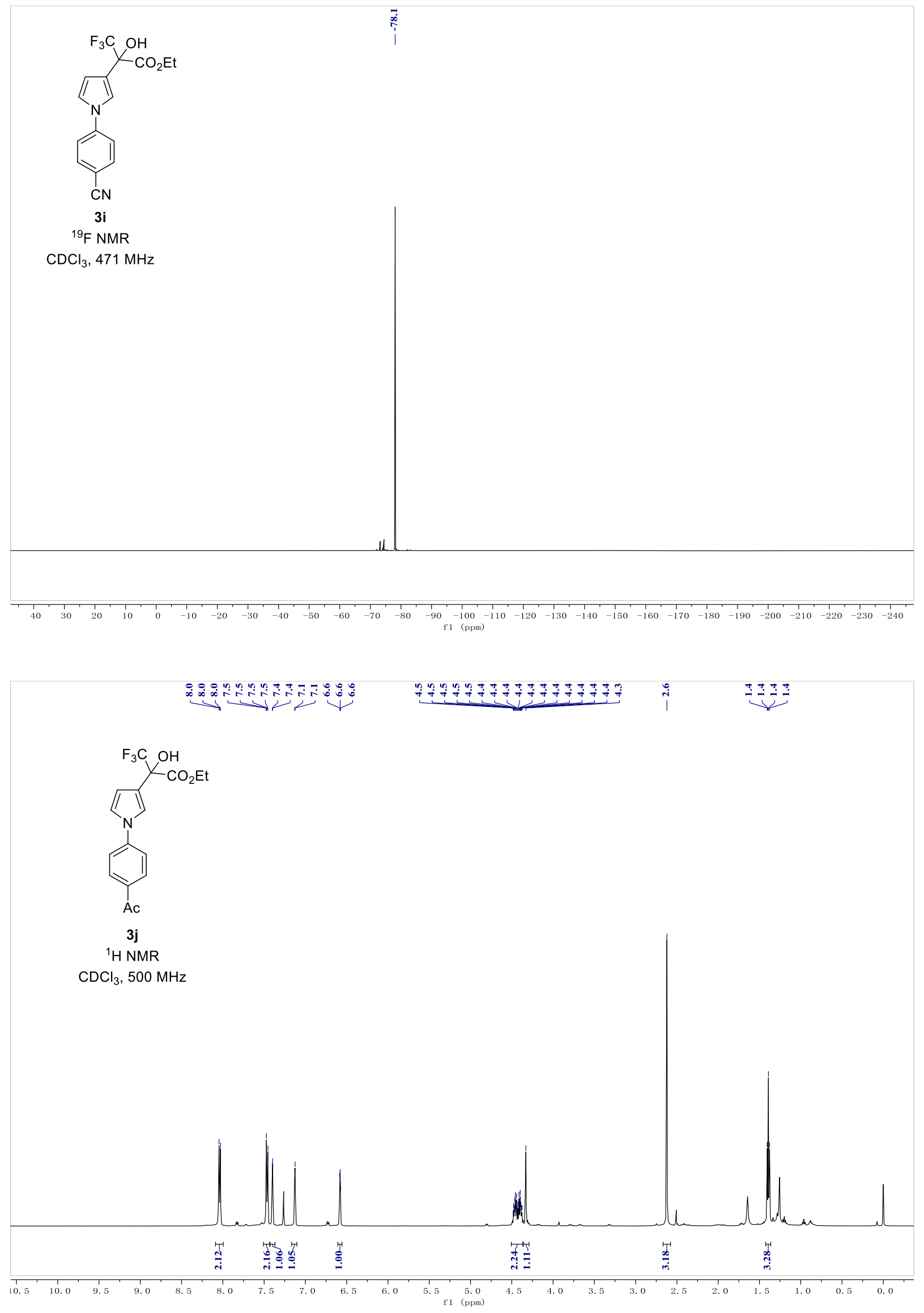



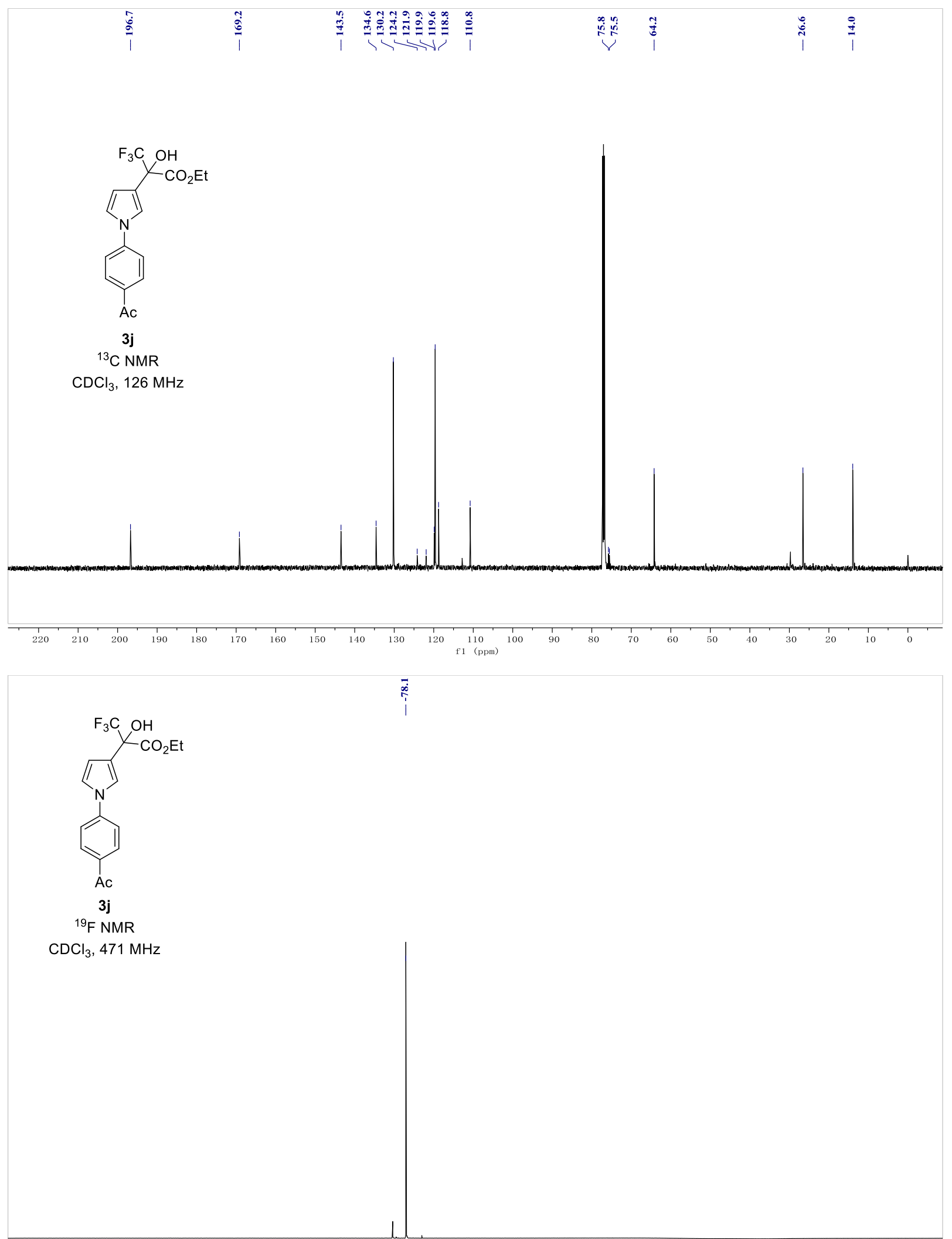

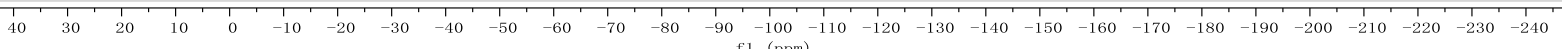




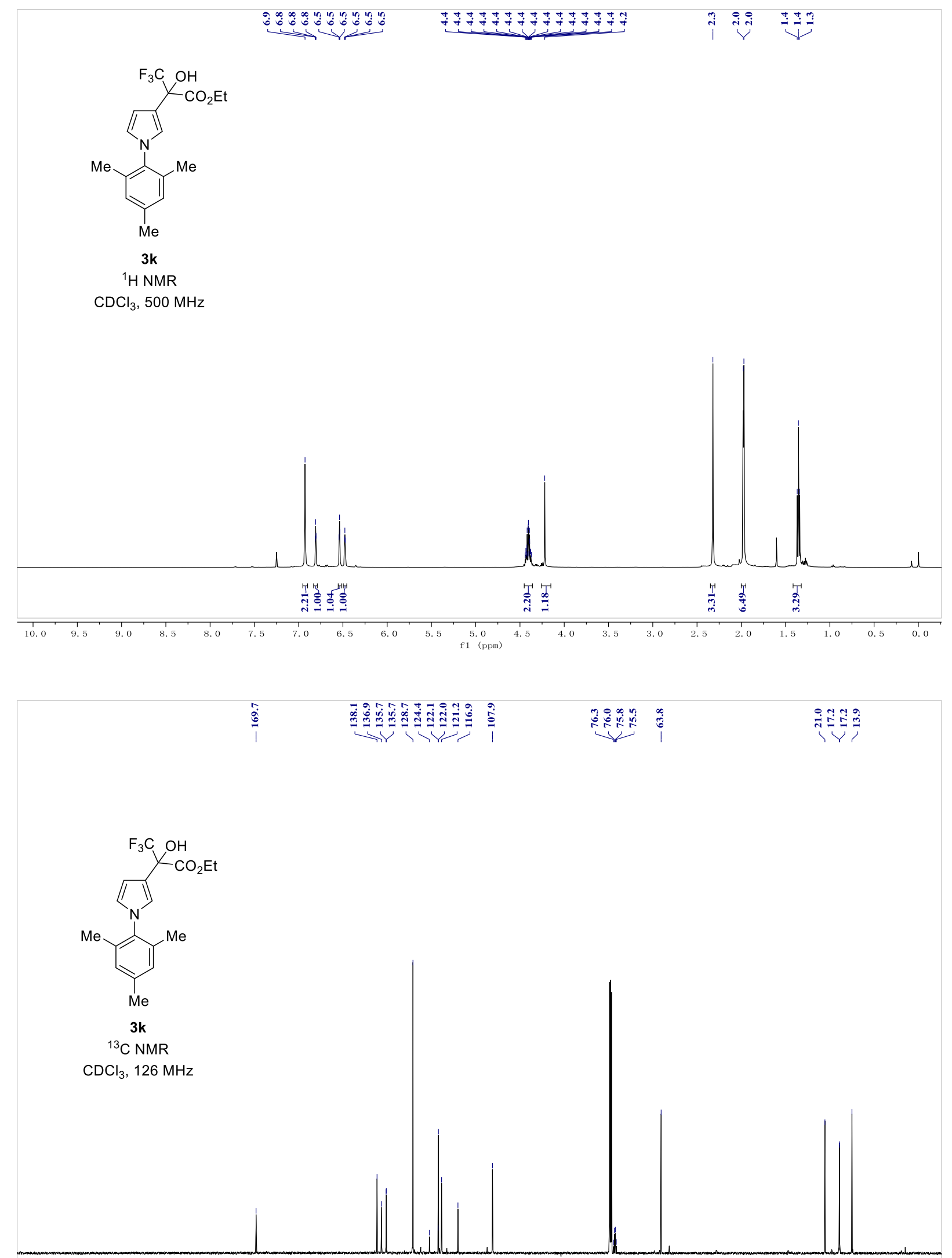

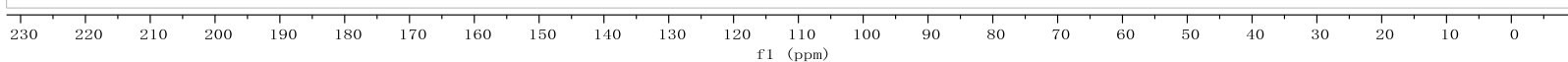




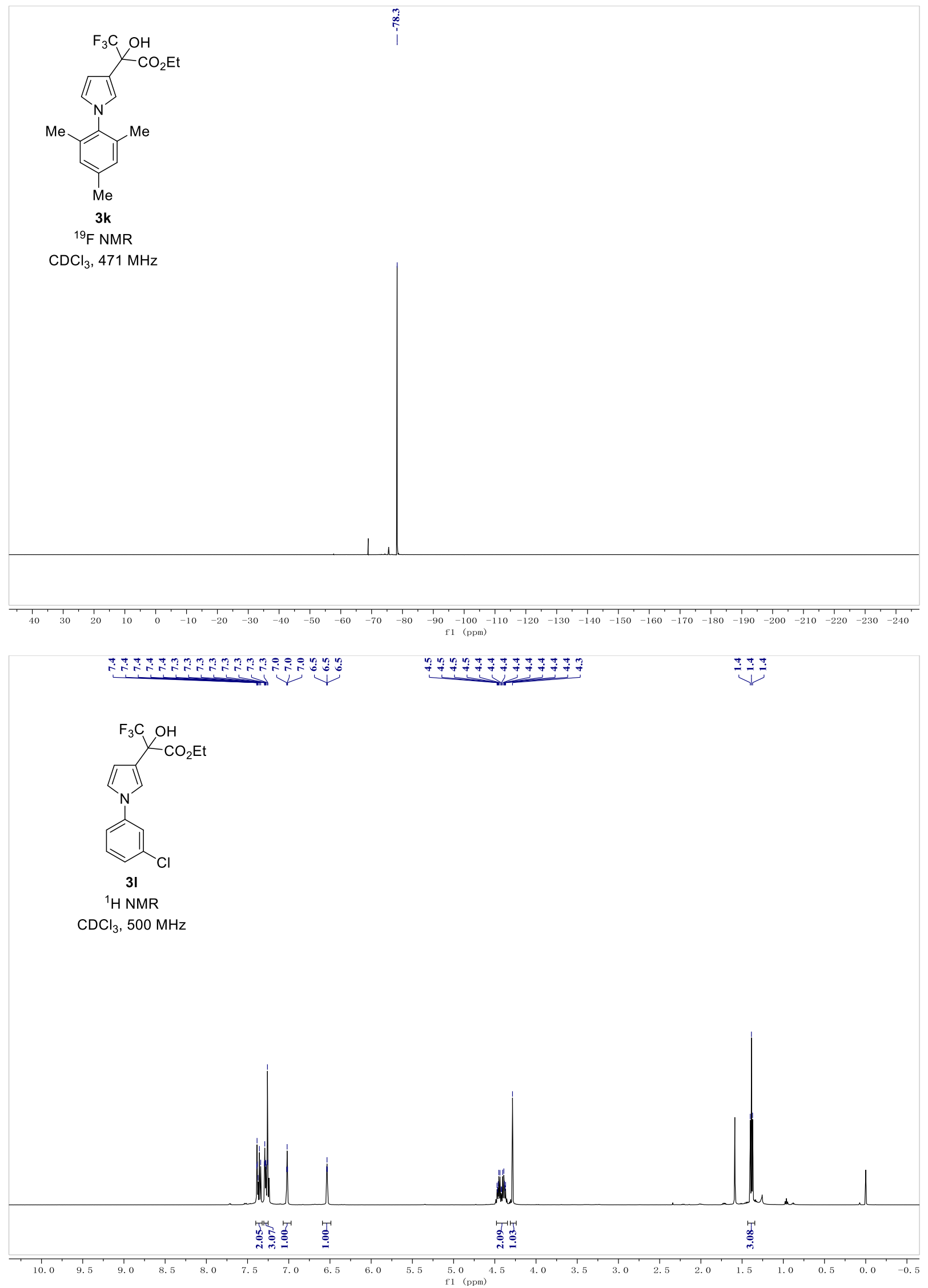



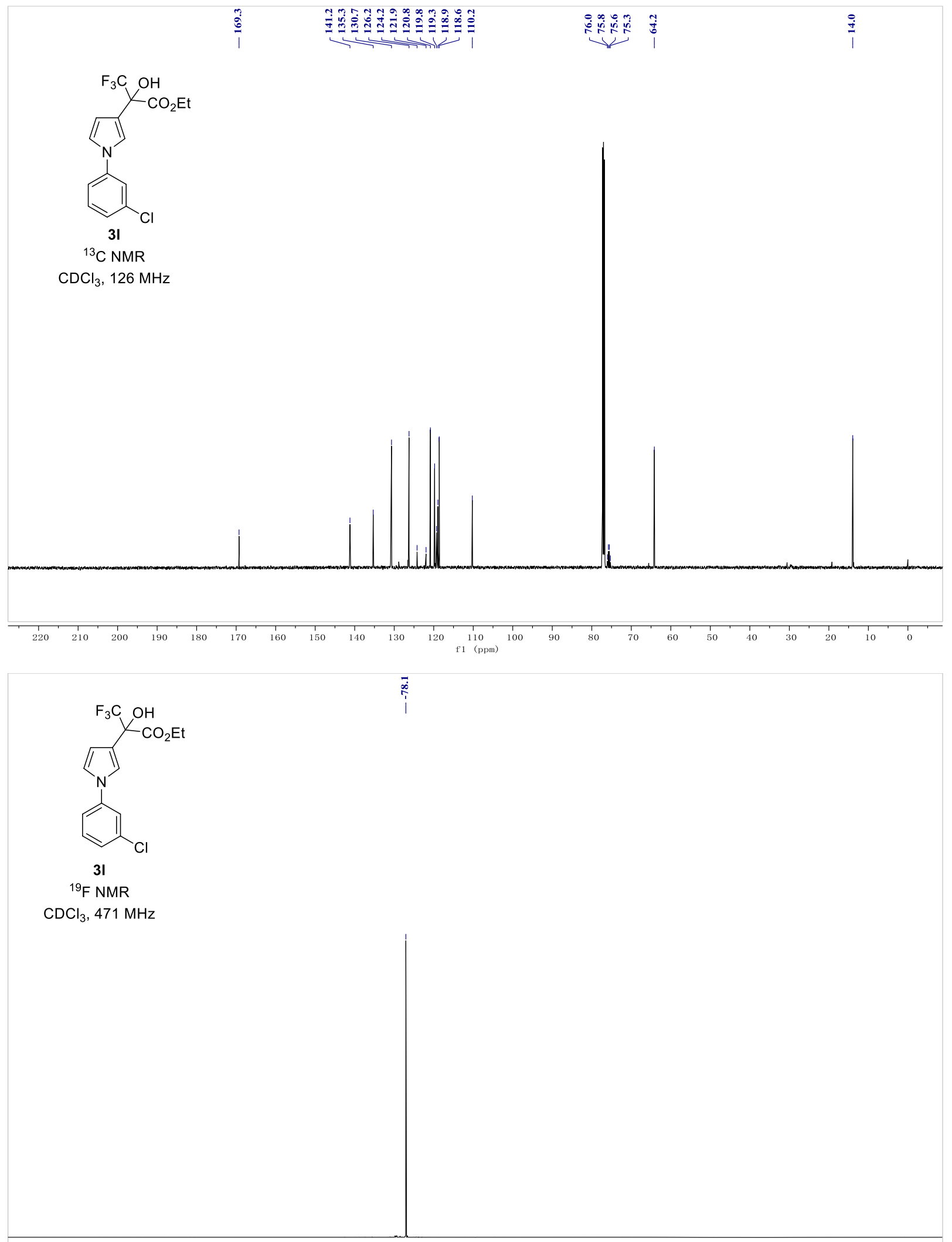

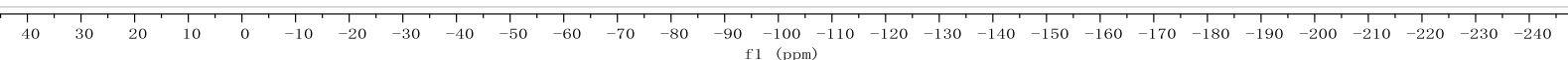



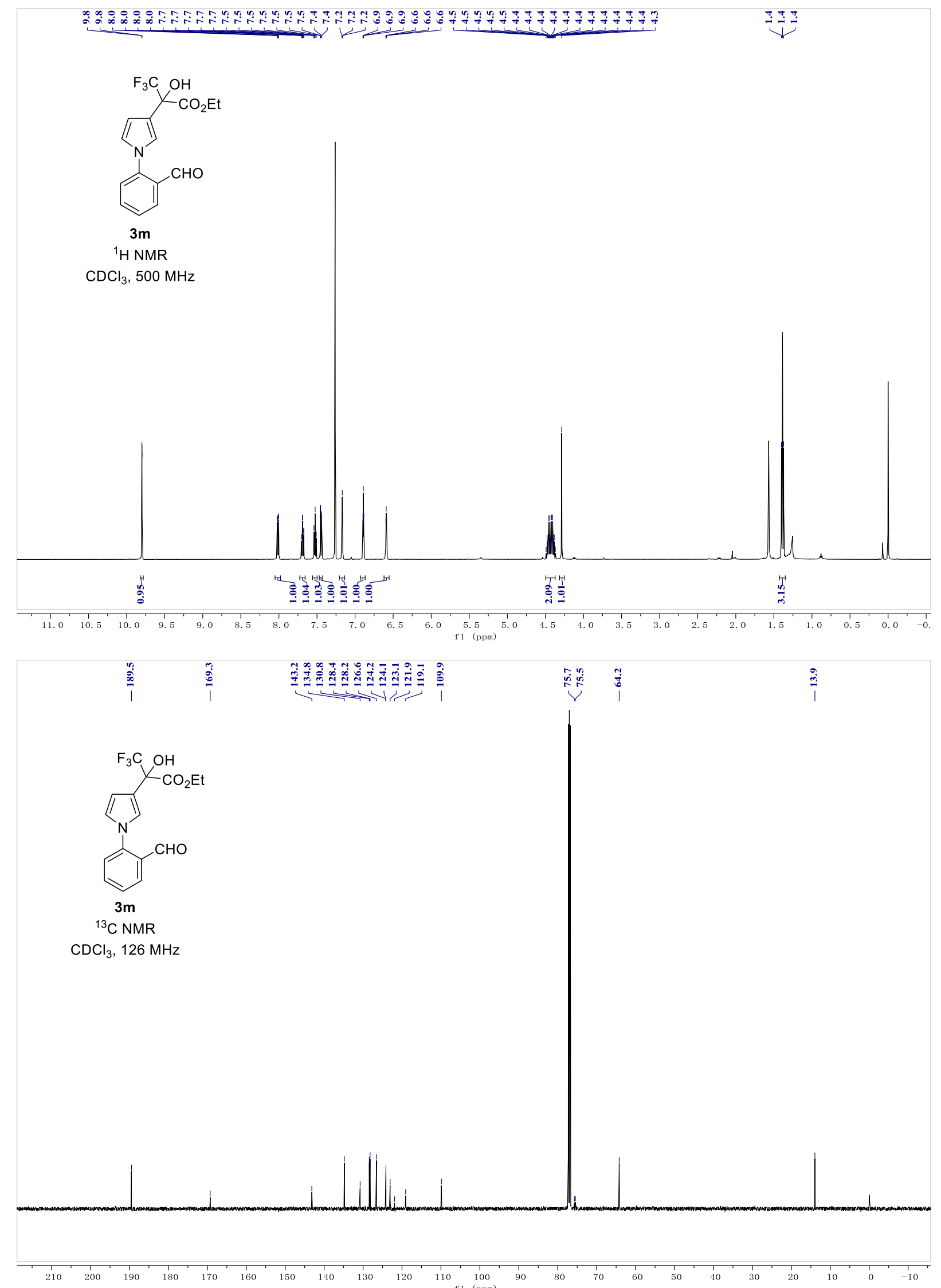


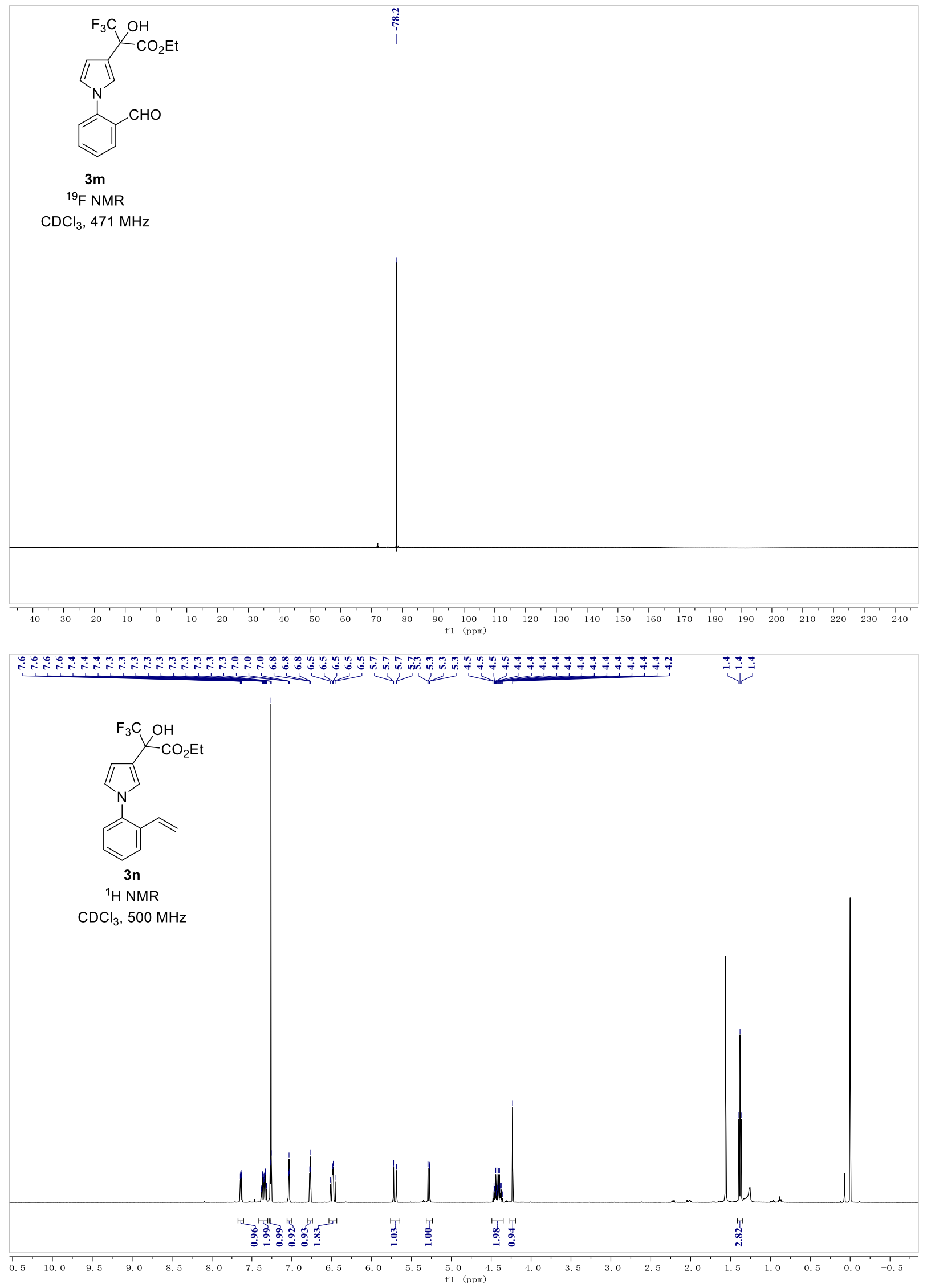



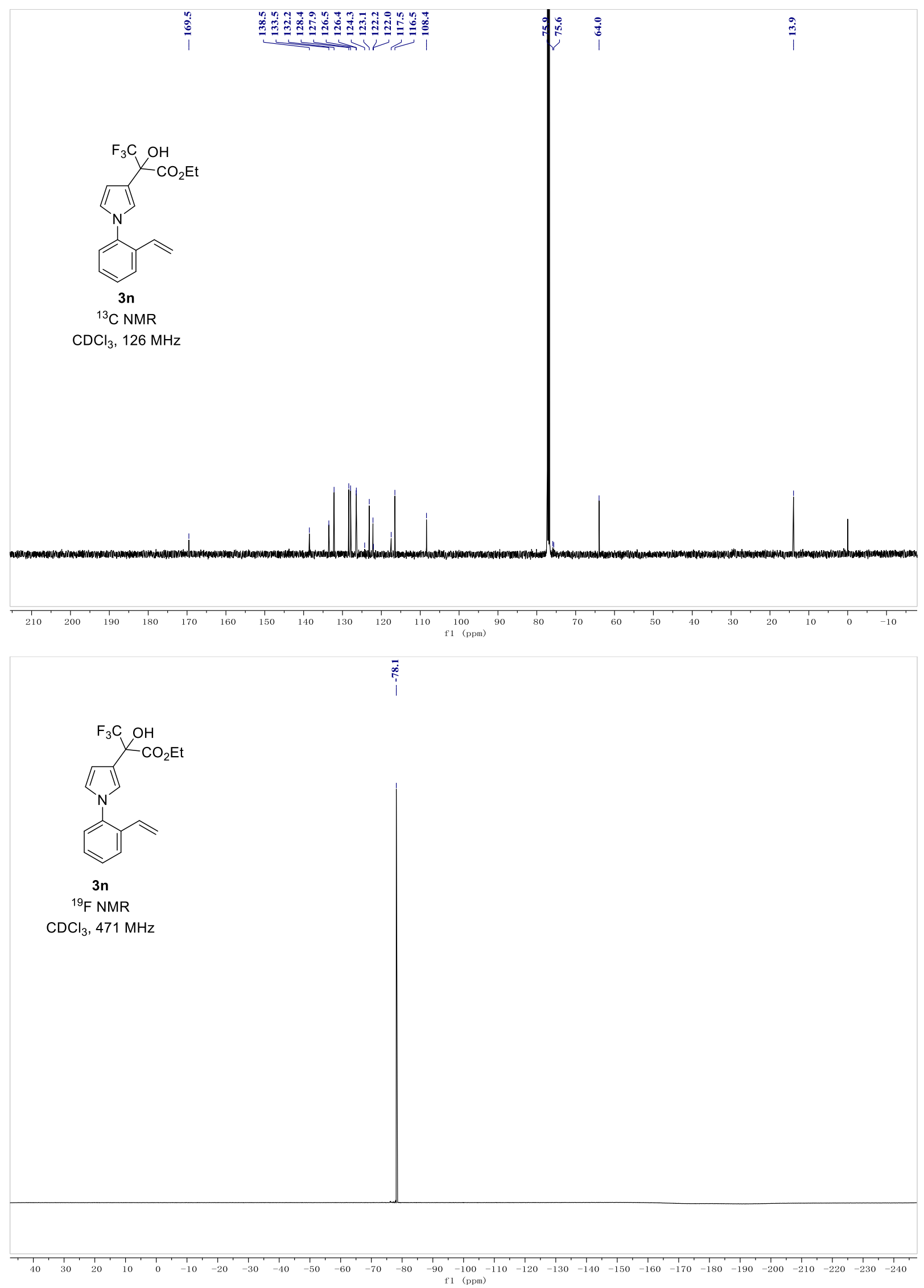

S25 

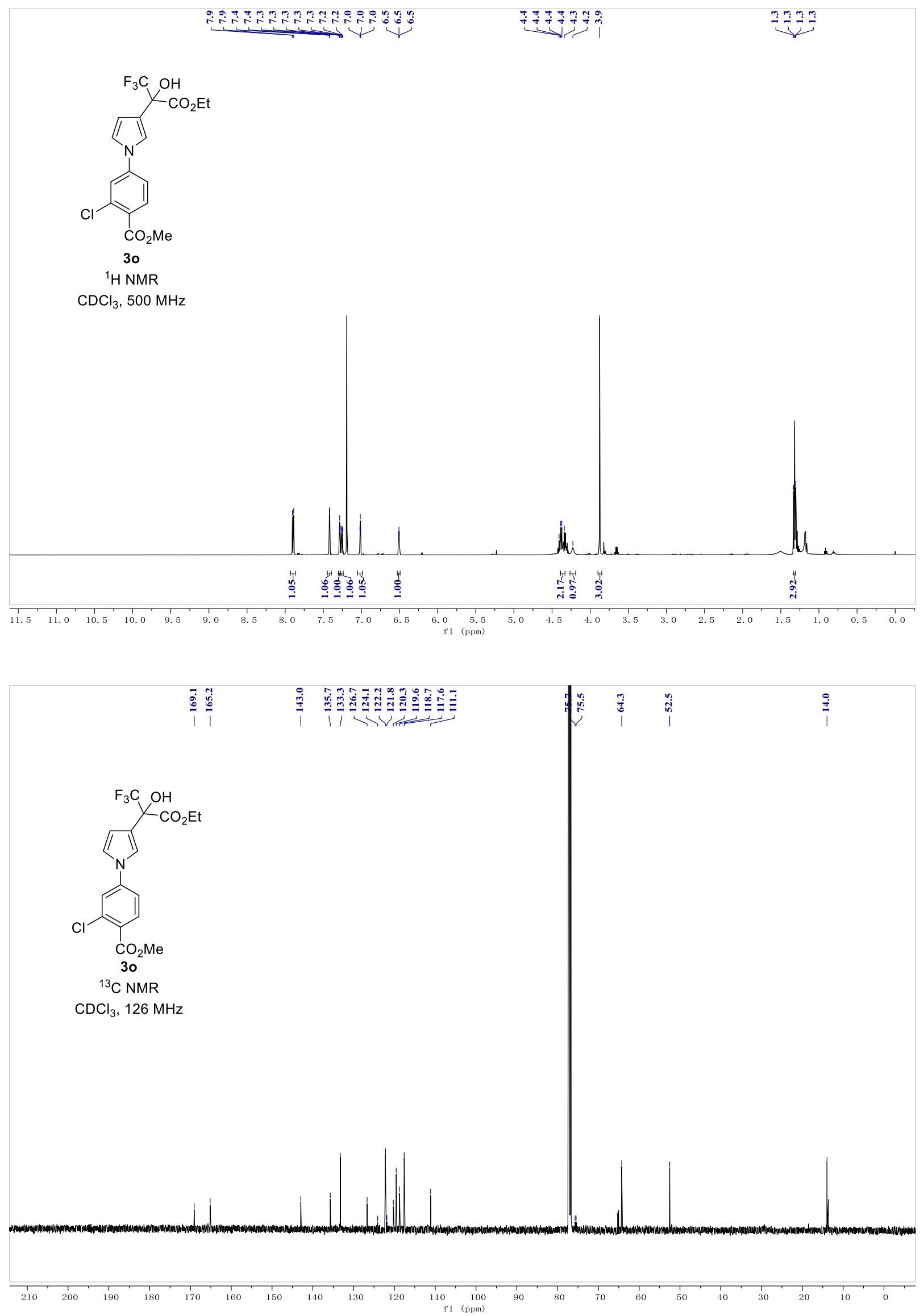


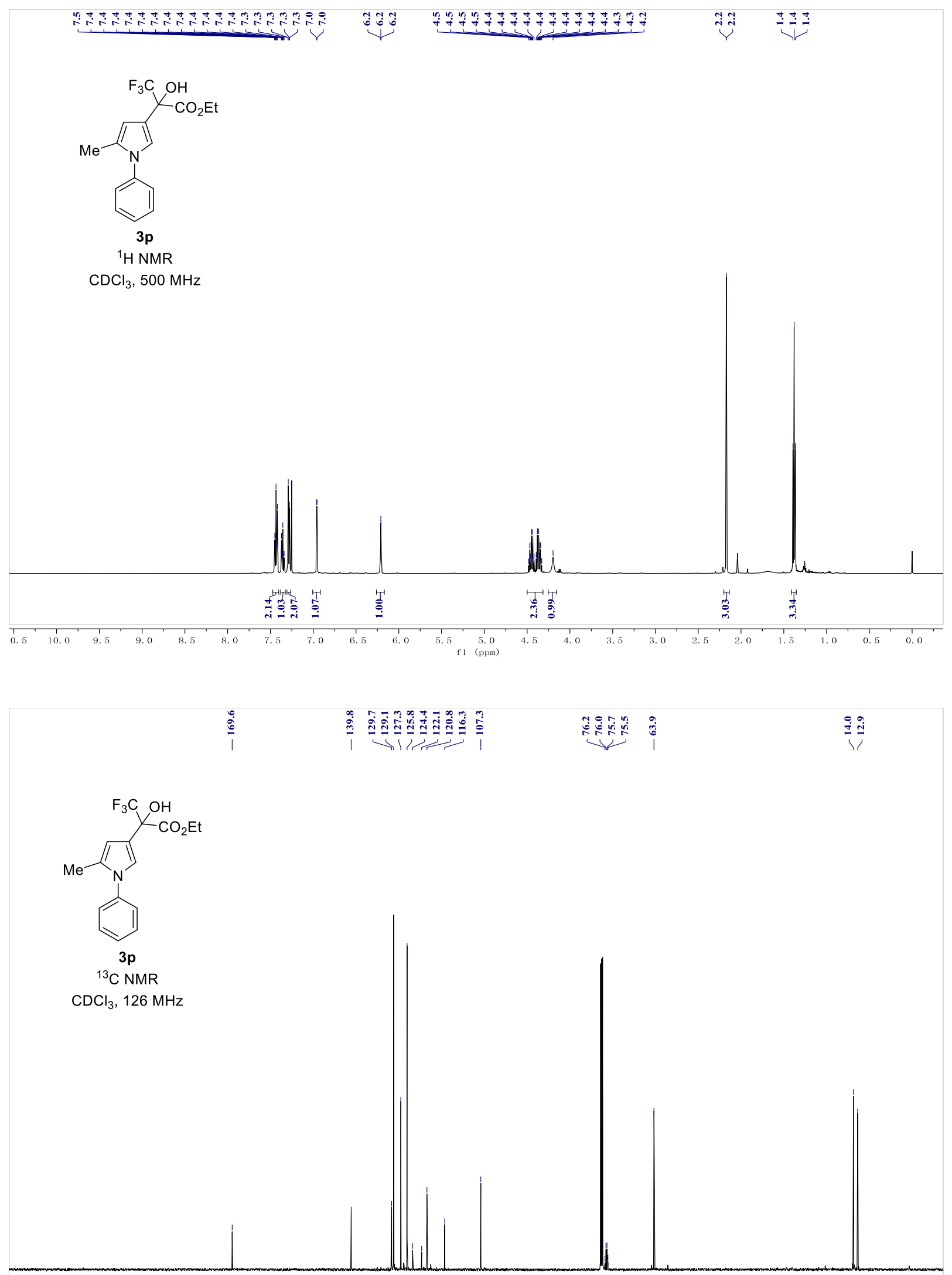

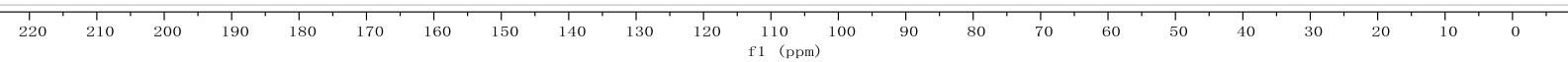



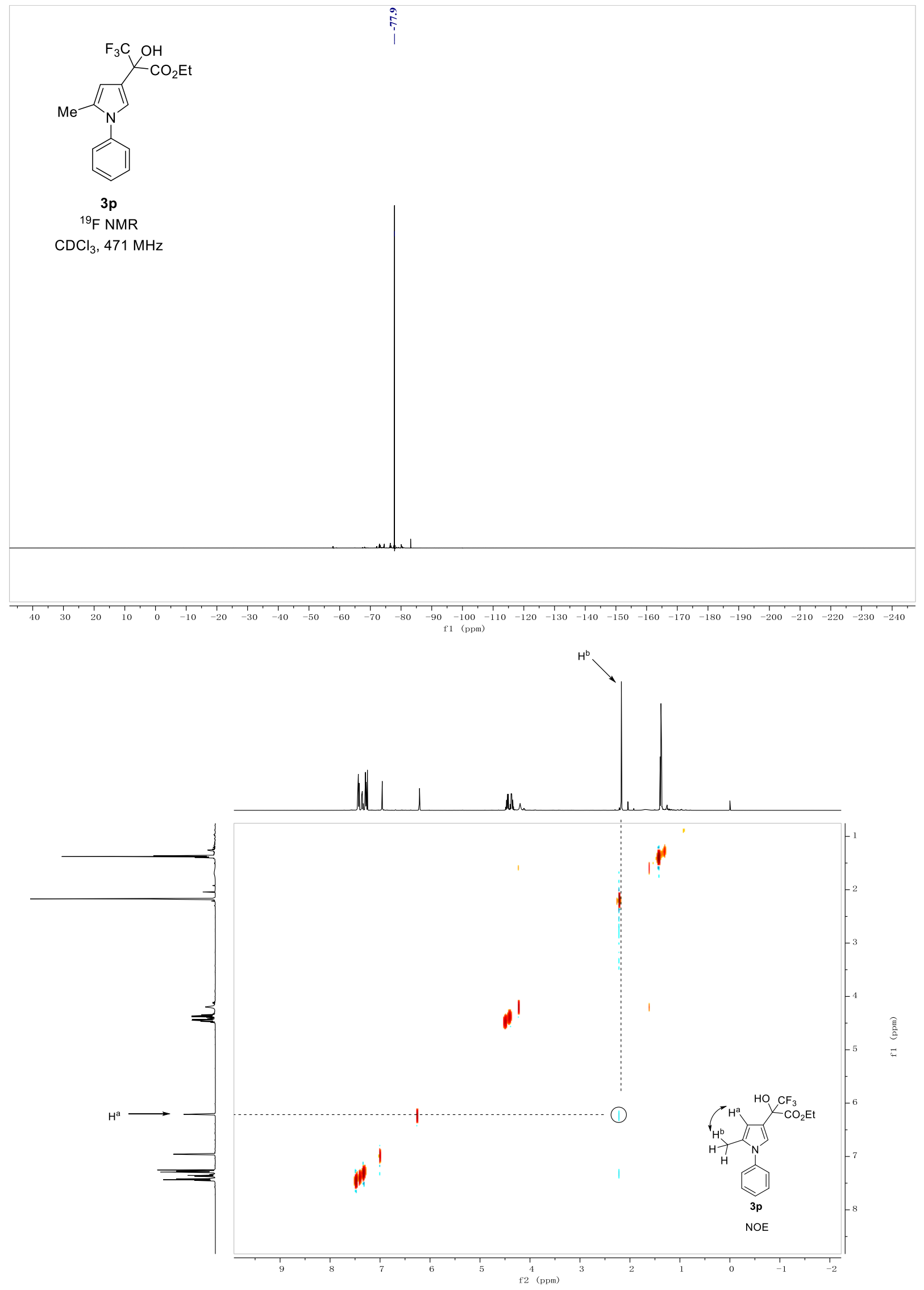

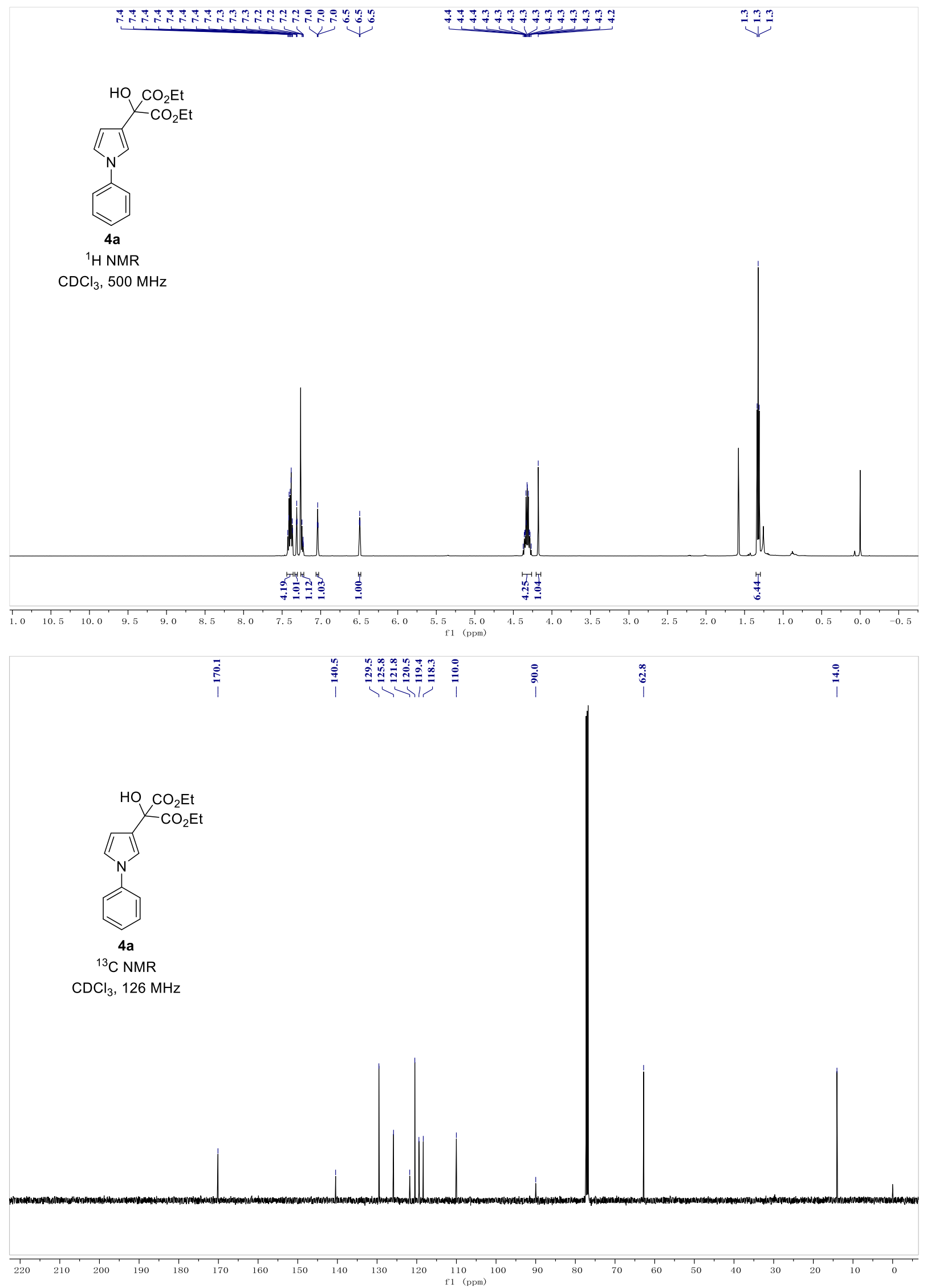

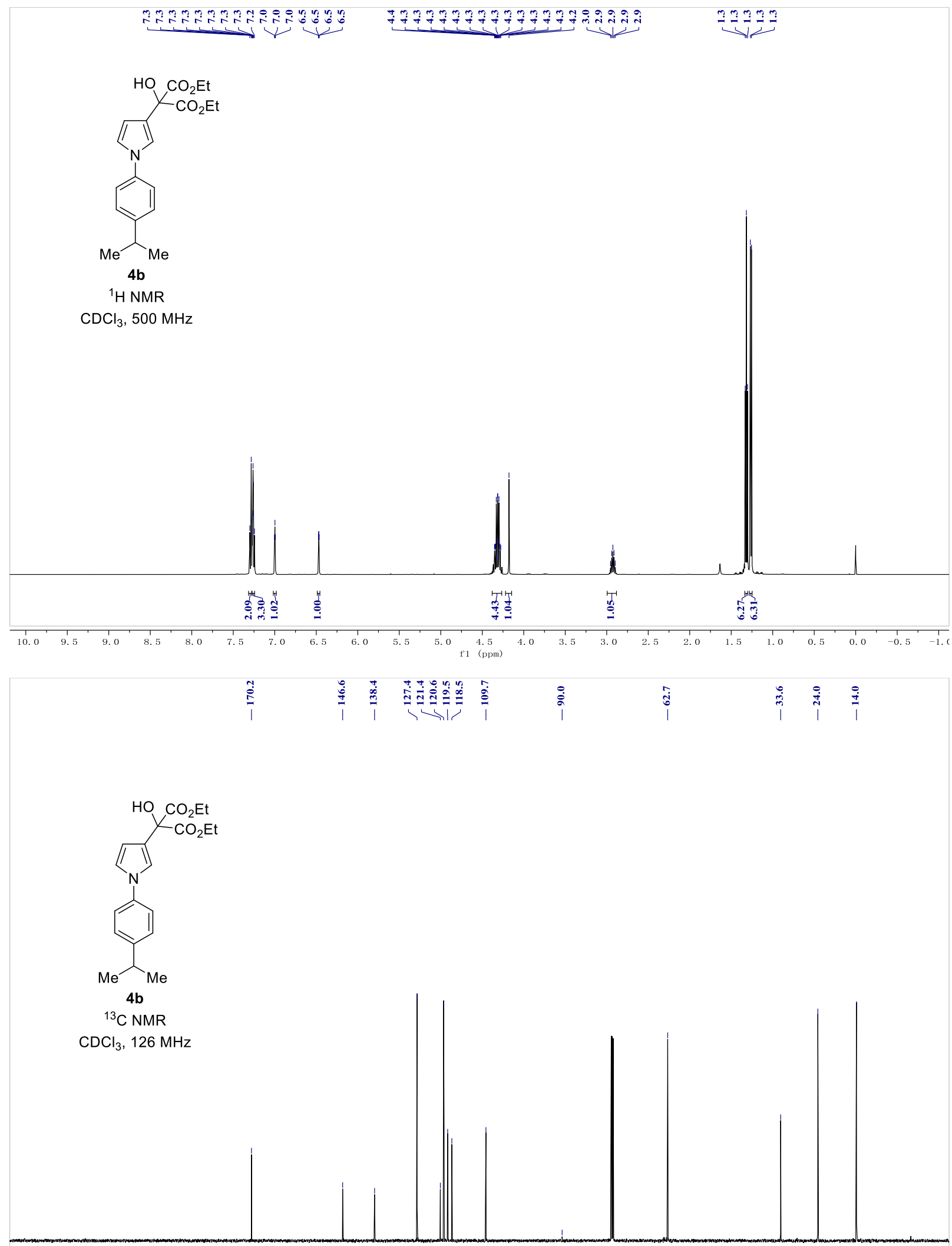

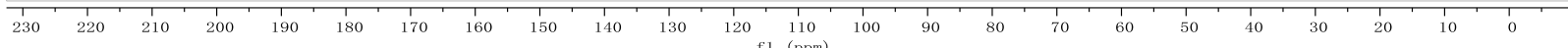



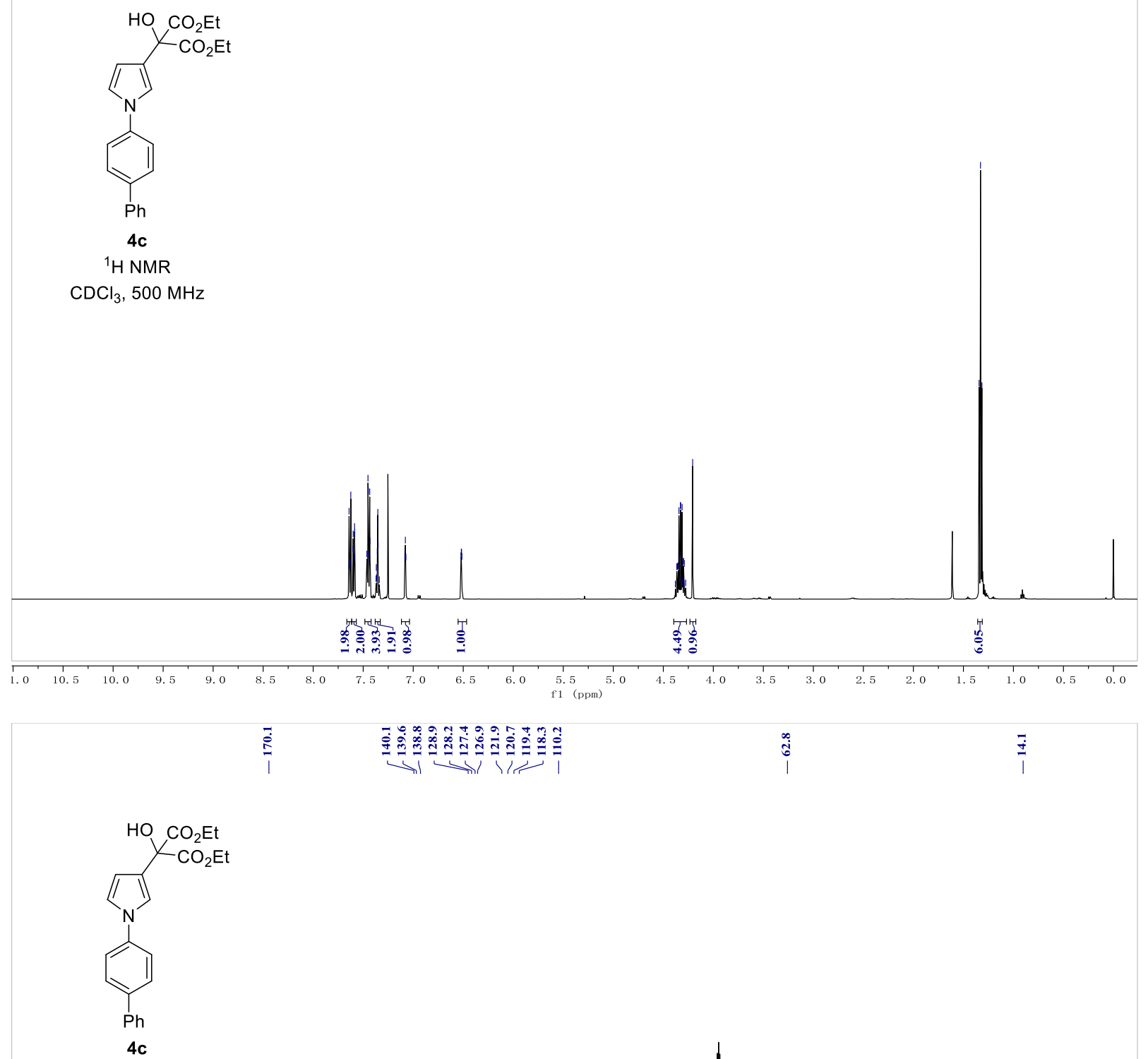

${ }^{13} \mathrm{C} \mathrm{NMR}$ $\mathrm{CDCl}_{3}, 126 \mathrm{MHz}$

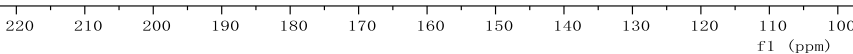



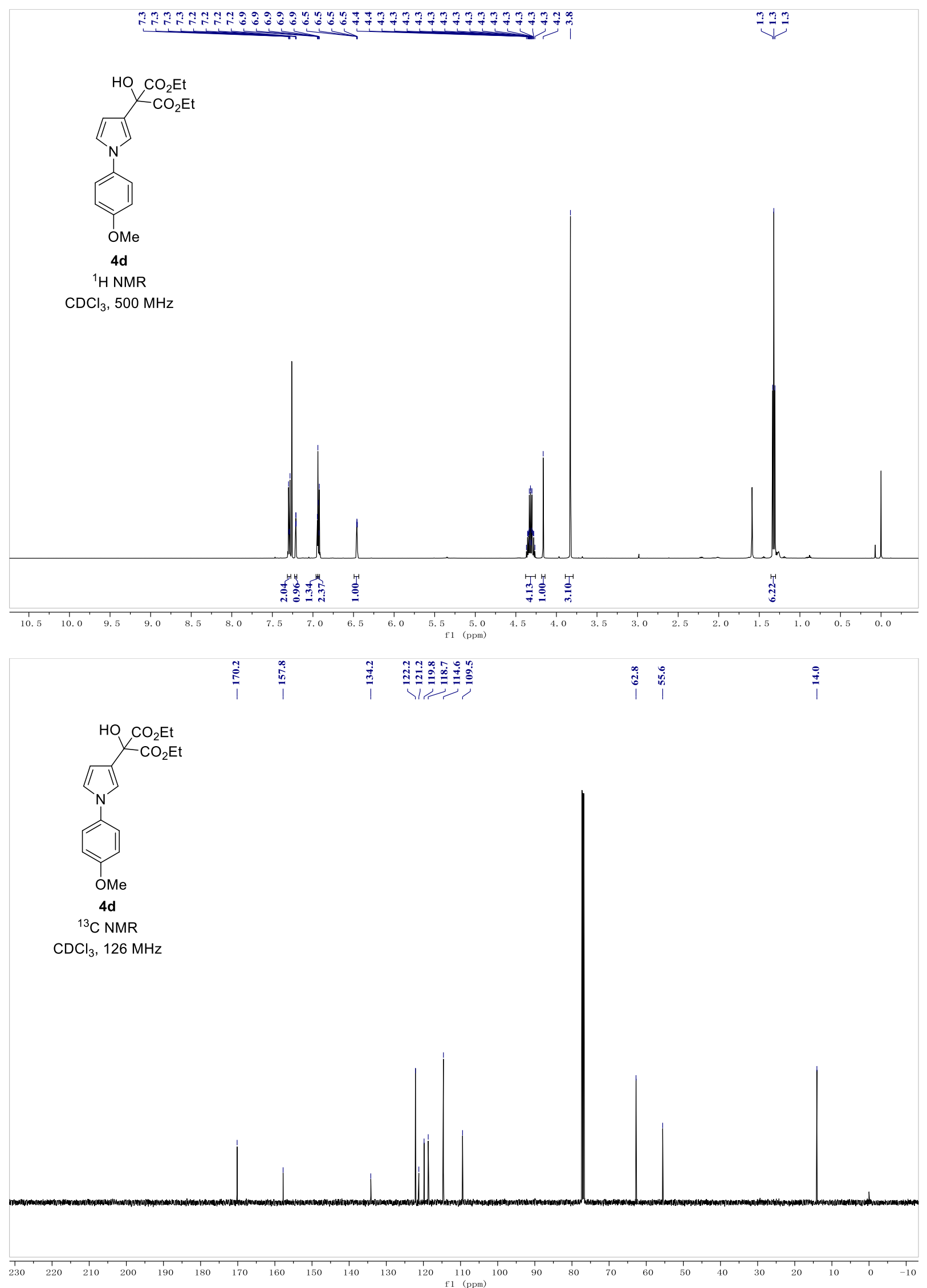


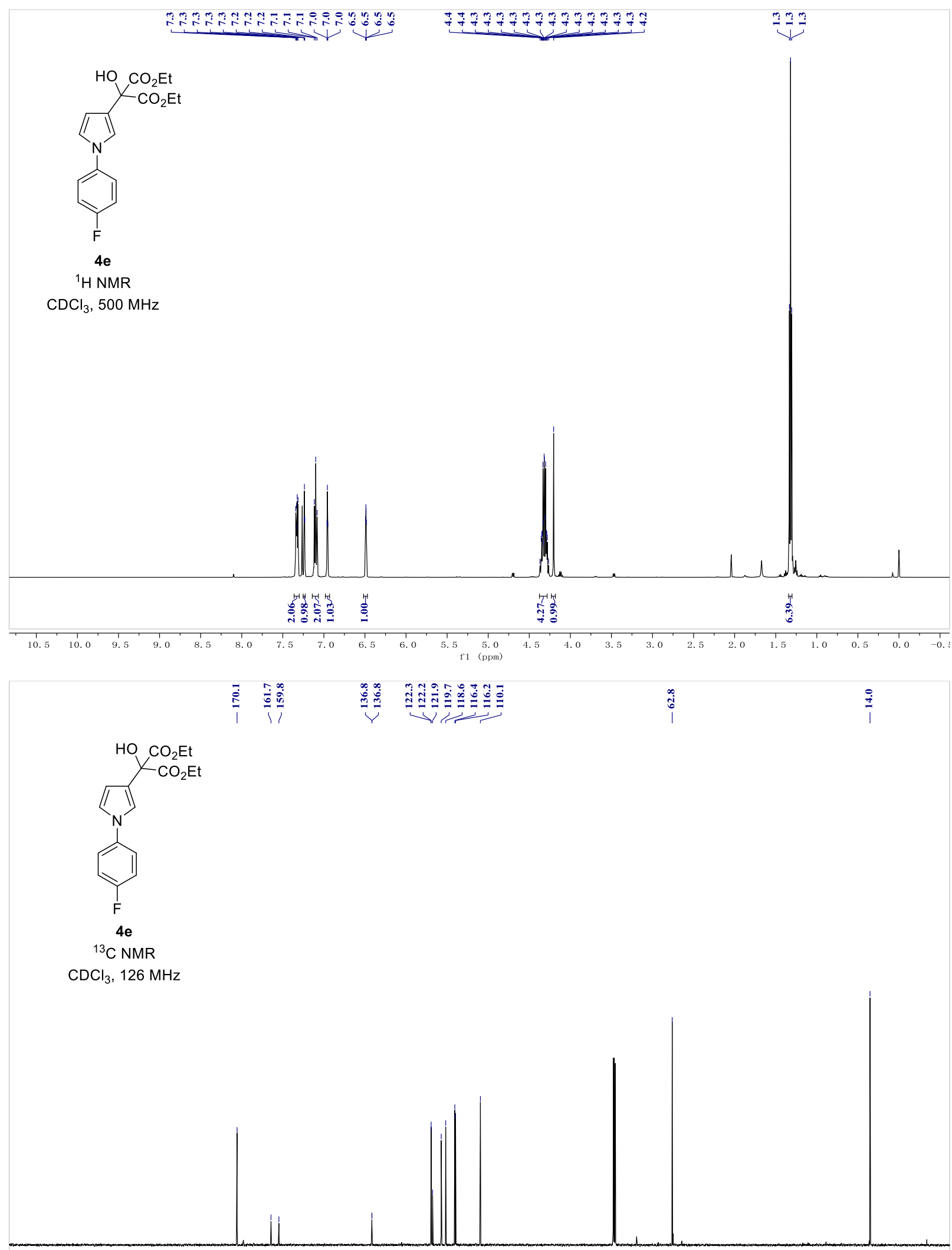

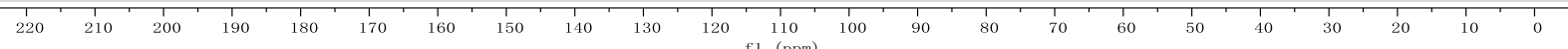



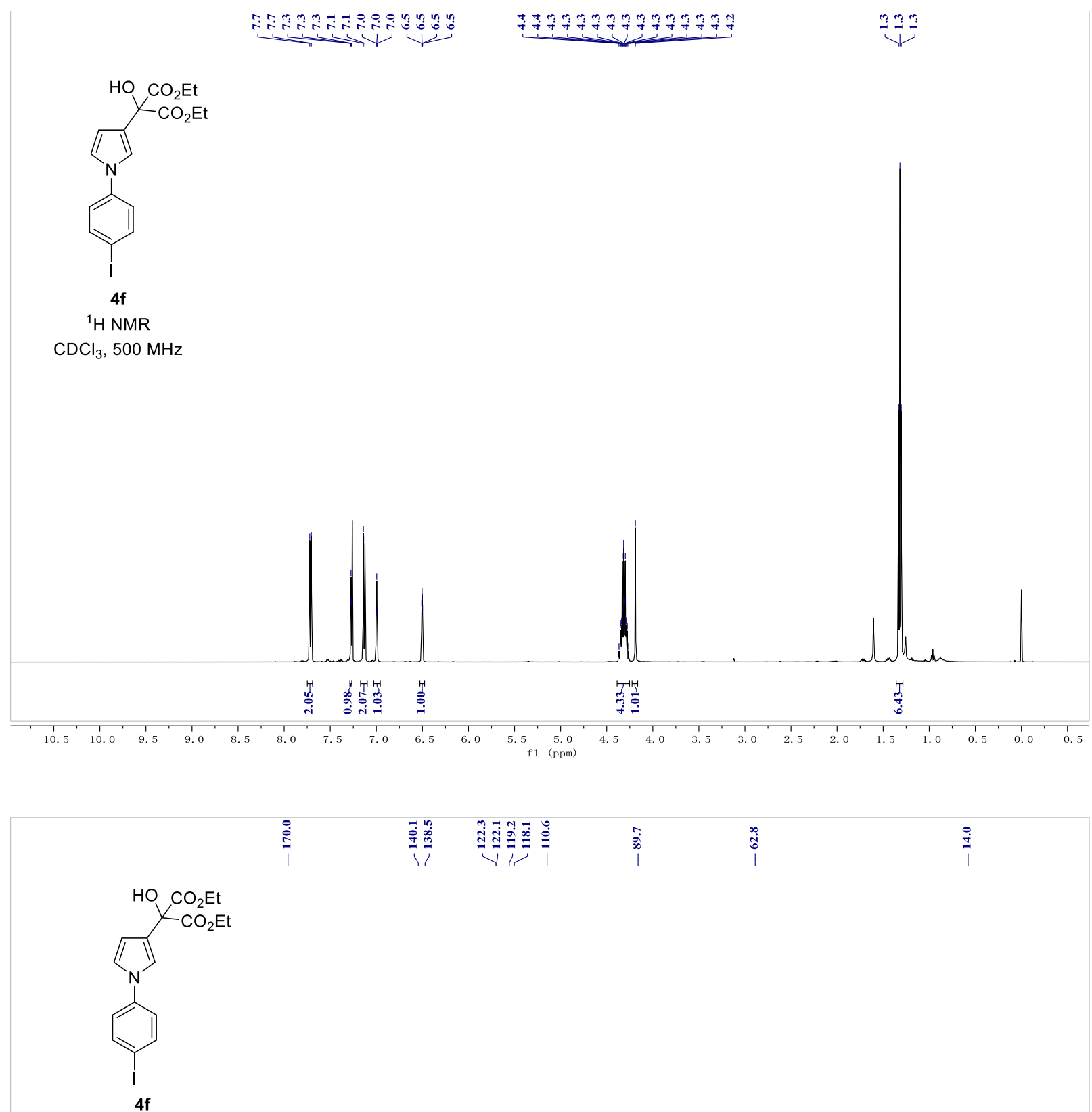

${ }^{13} \mathrm{C}$ NMR

$\mathrm{CDCl}_{3}, 126 \mathrm{MHz}$

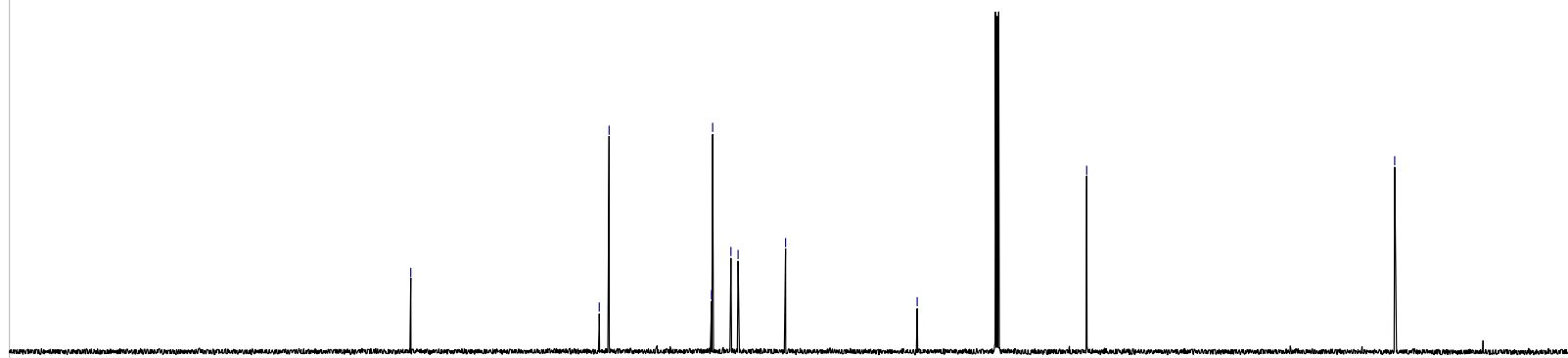

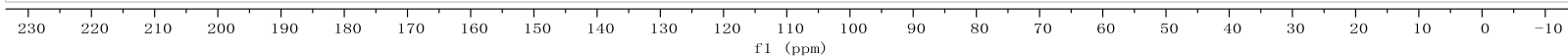




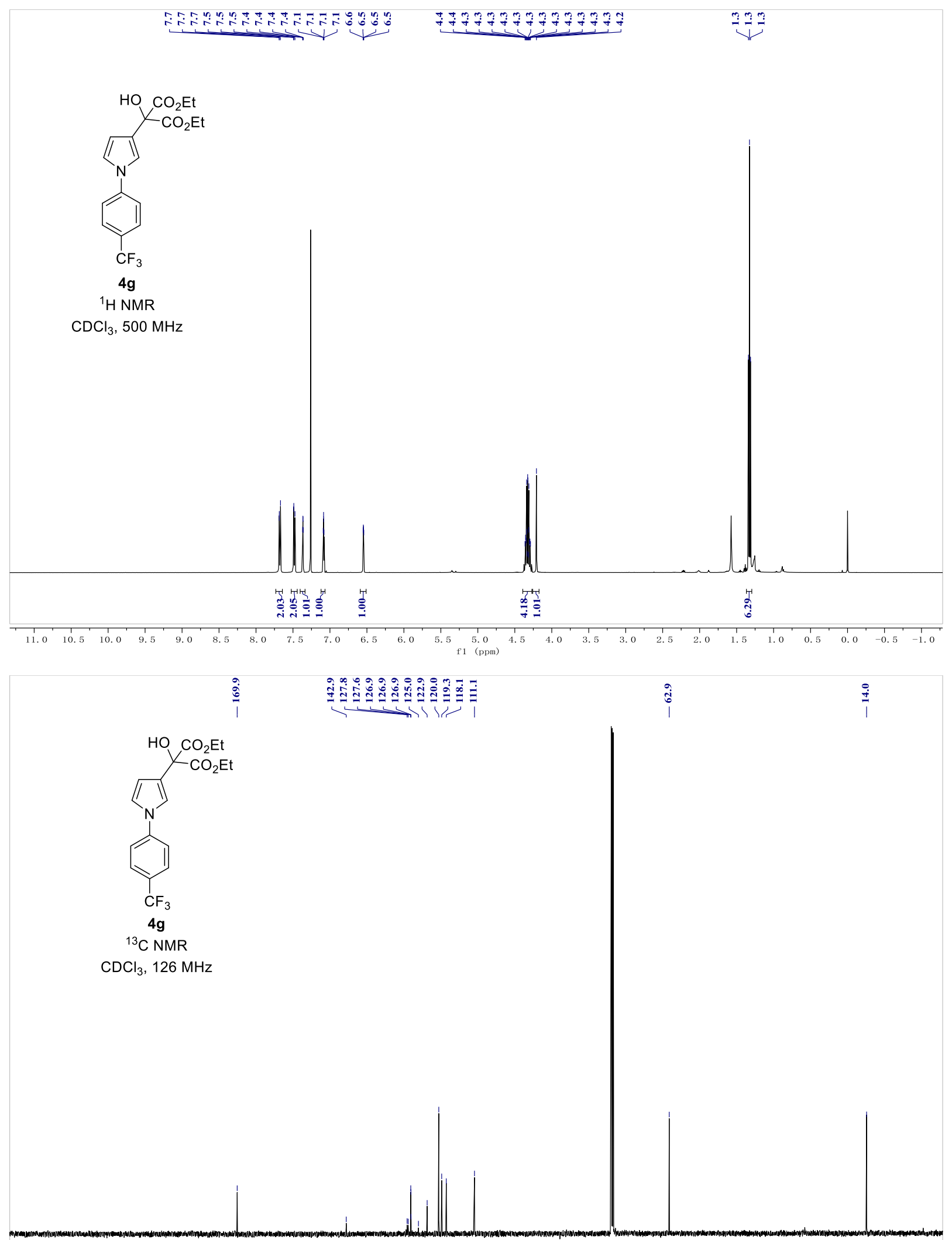

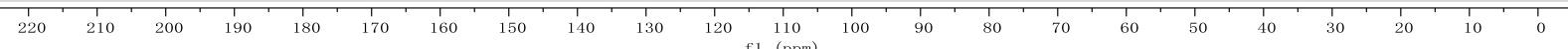



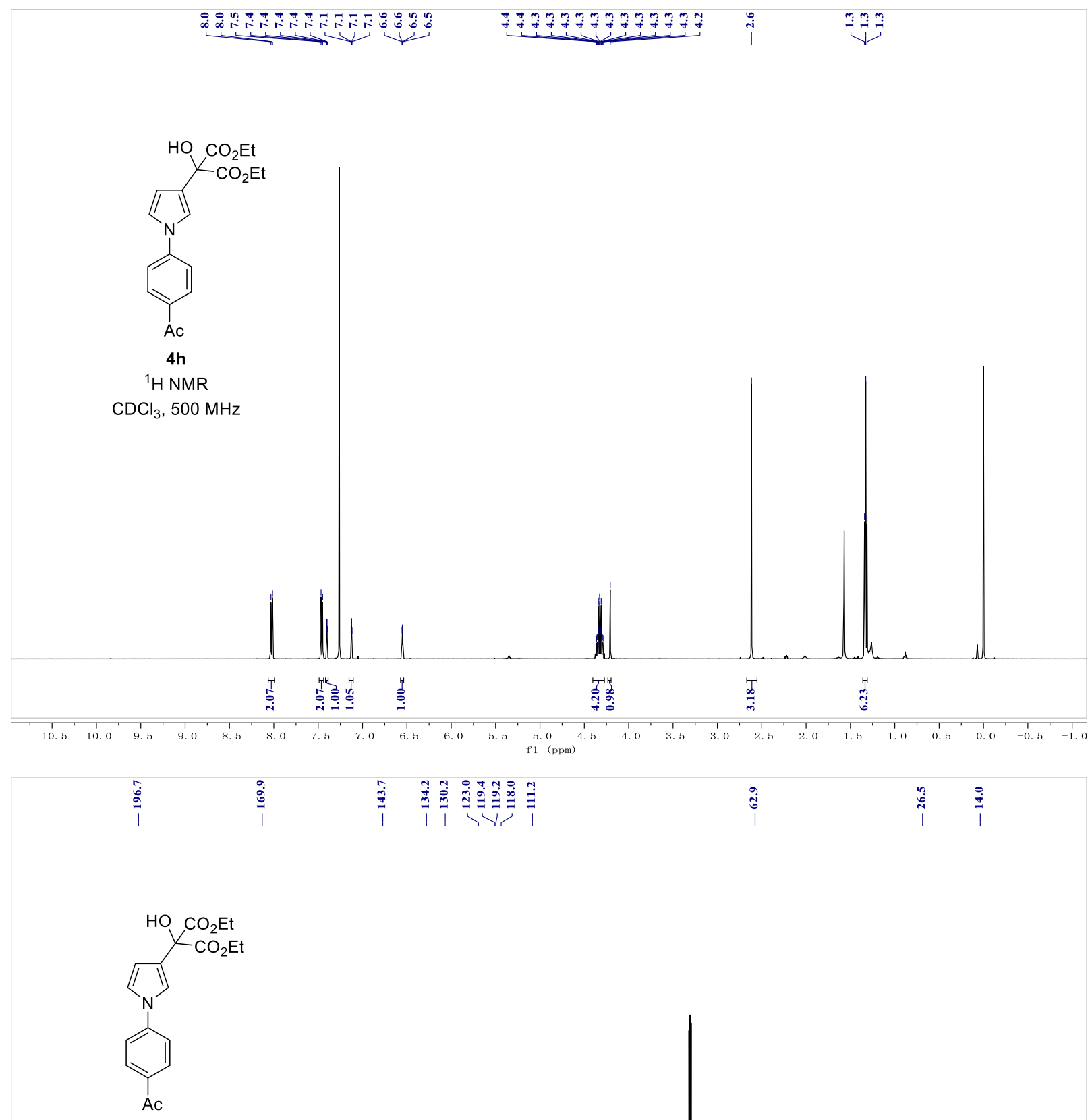

4h

${ }^{13} \mathrm{C}$ NMR

$\mathrm{CDCl}_{3}, 126 \mathrm{MHz}$ 


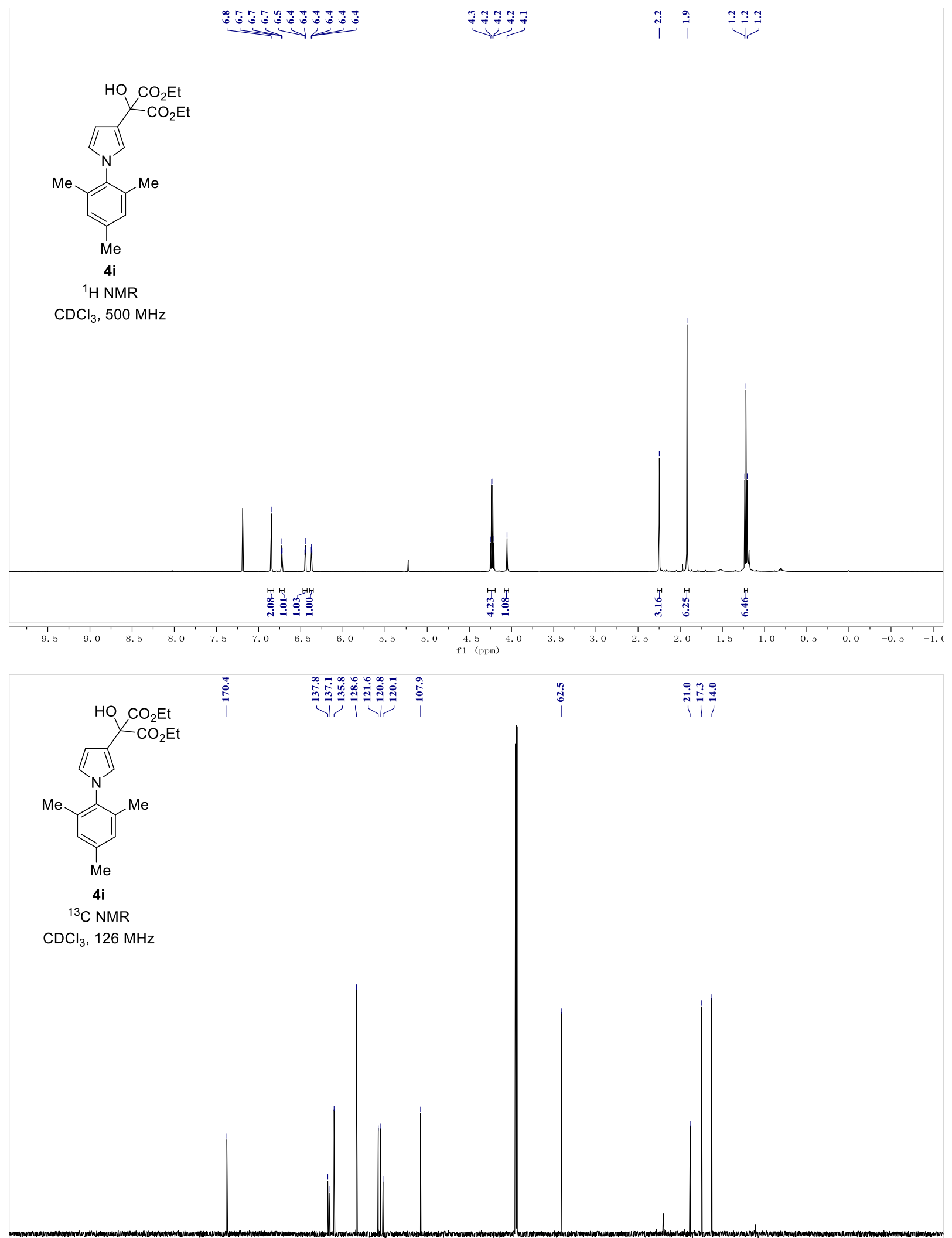

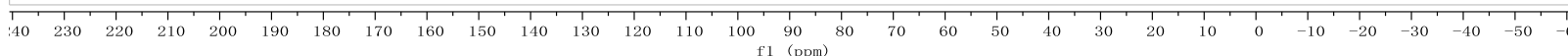



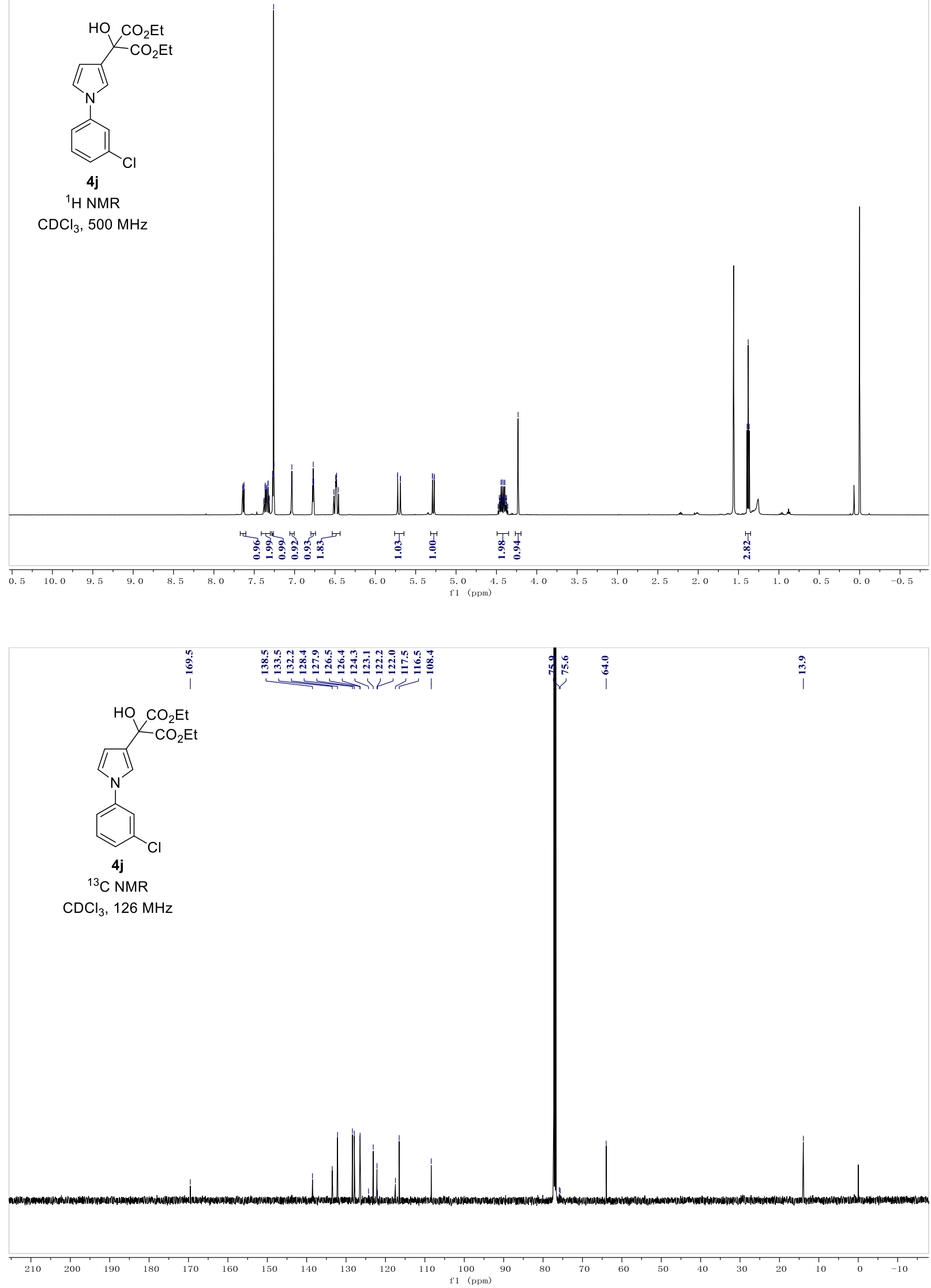


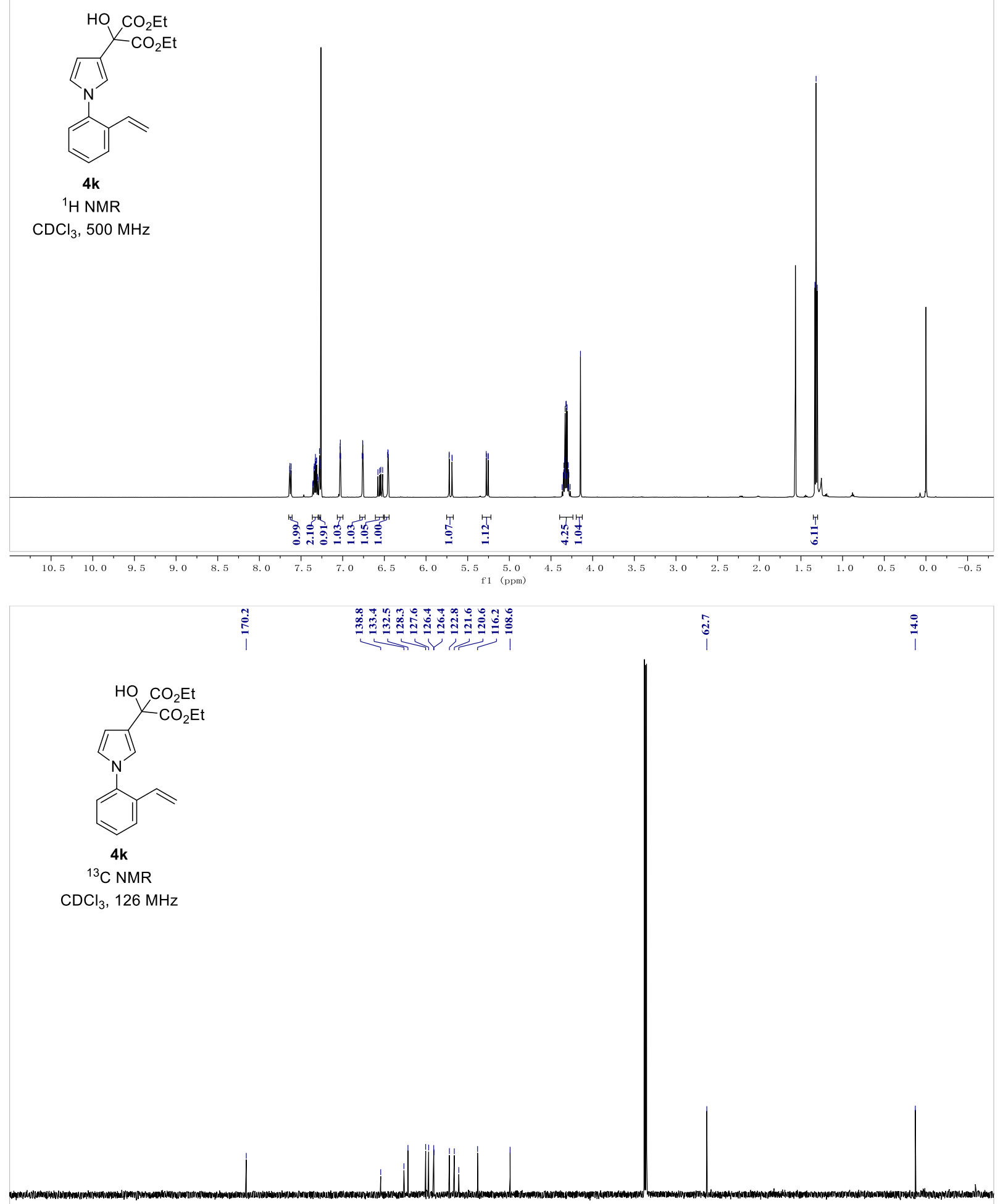

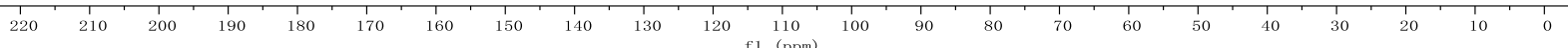




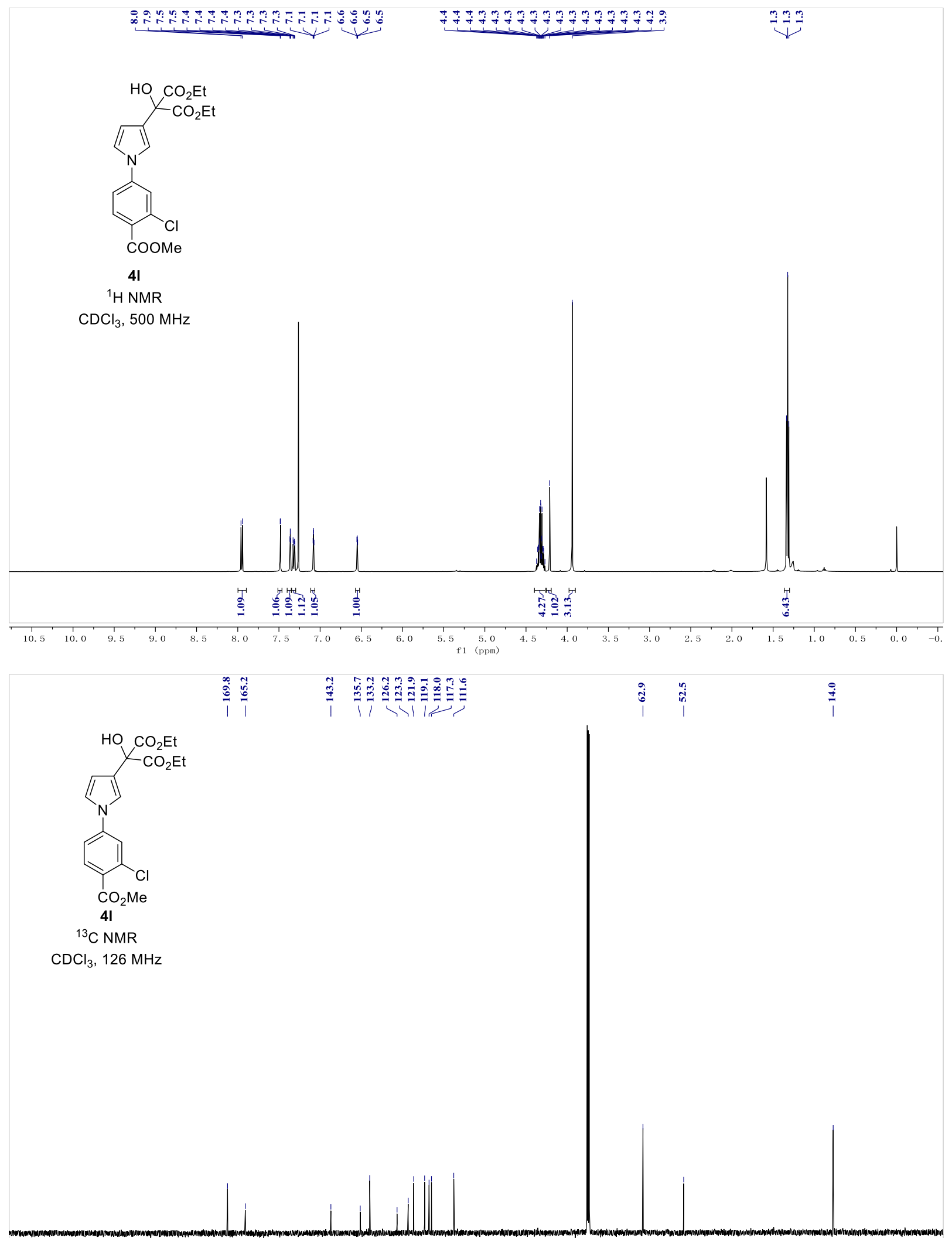

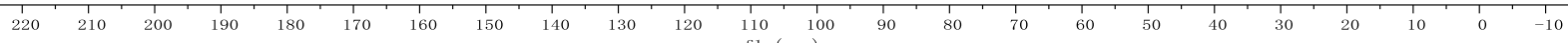



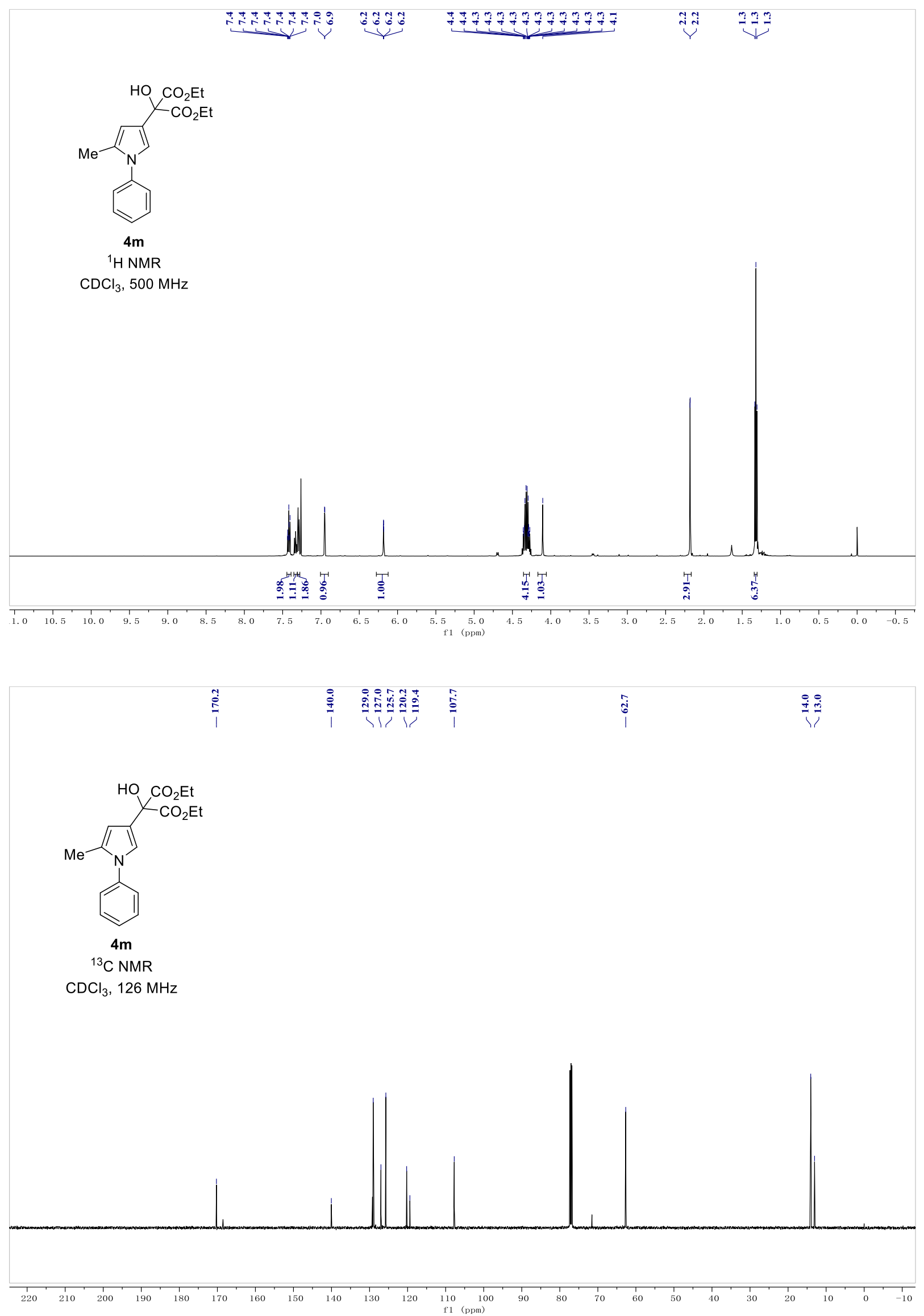


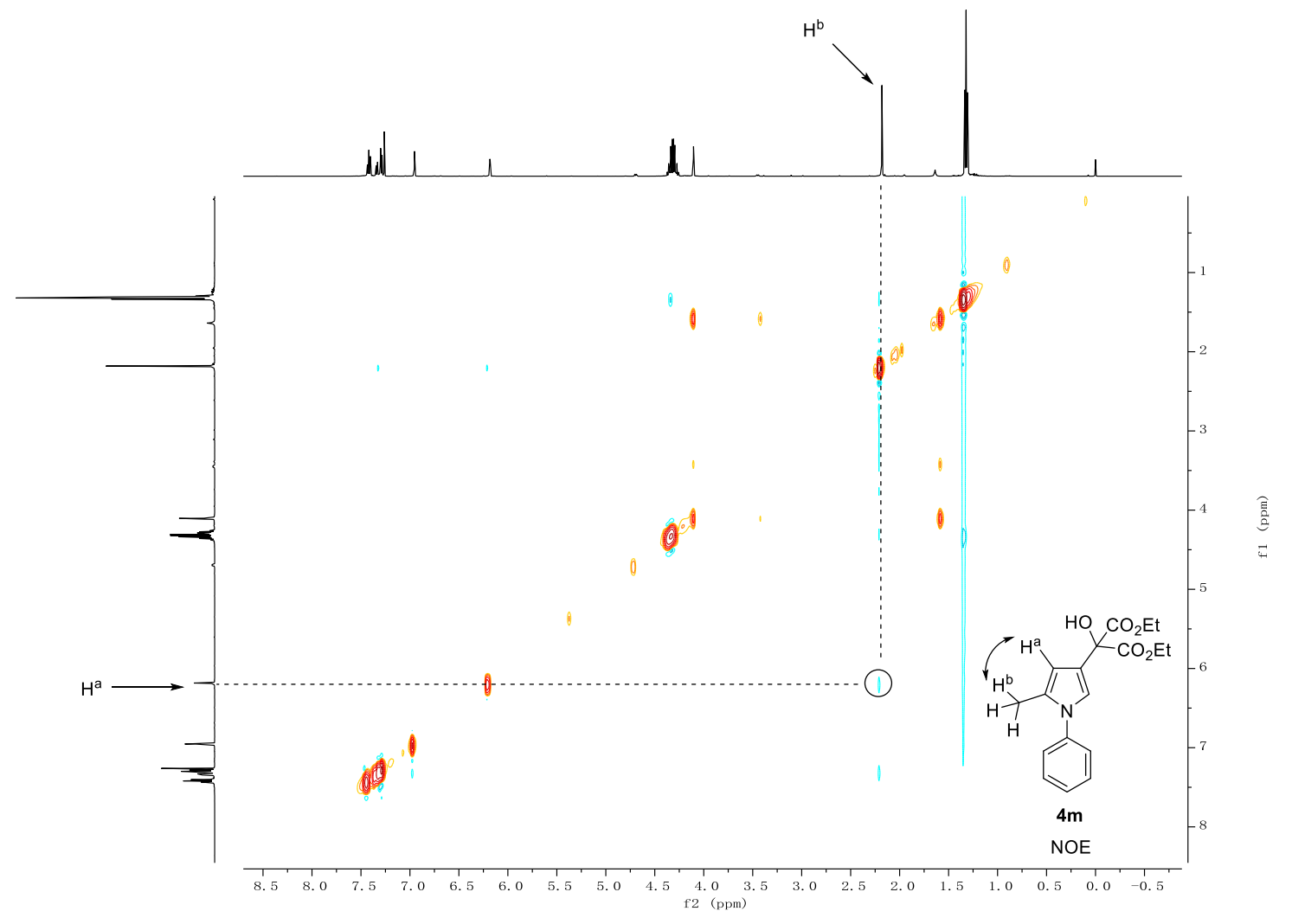



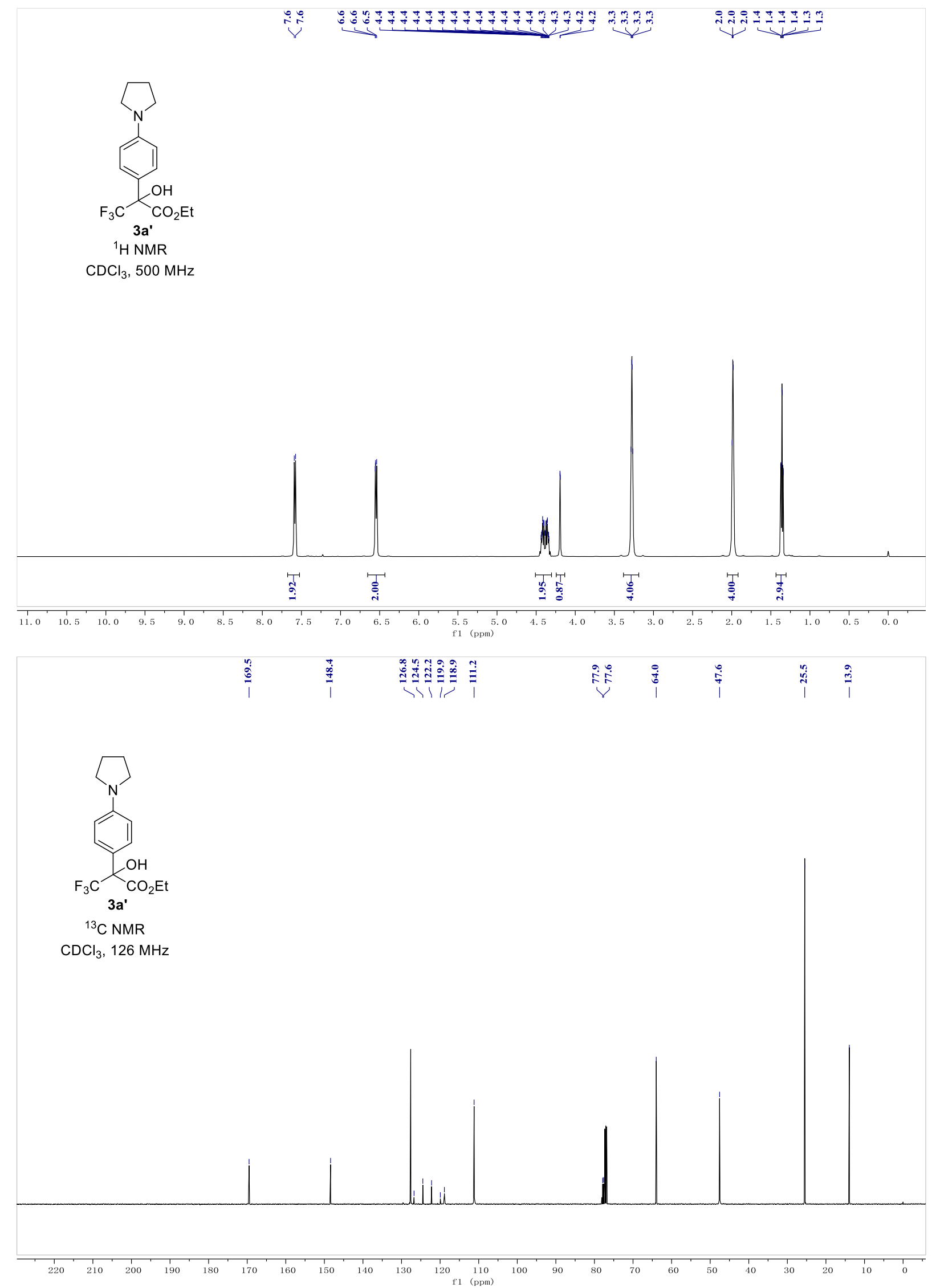


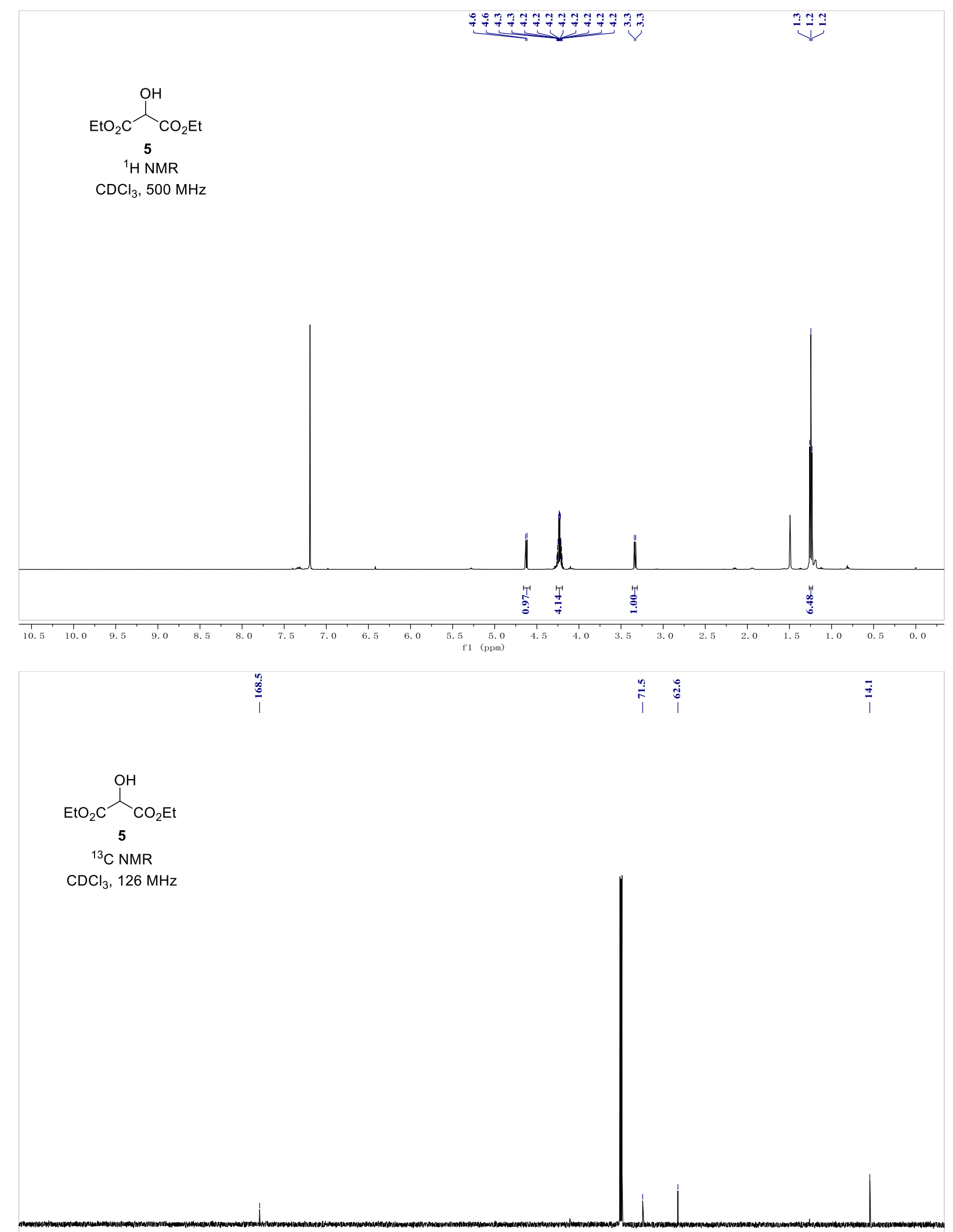

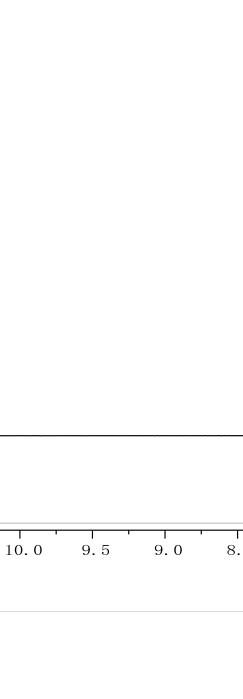

f1 $(\mathrm{ppm})$ 